\title{
Vibrational Dynamics and Heat Capacity of Poly(L-lysine)
}

\author{
Navnit Kumar Misra, Deepti Kapoor, Poonam Tandon, \\ and Vishwambhar Dayal GuPTA ${ }^{\dagger}$ \\ Department of Physics, University of Lucknow, Lucknow 226007 , India
}

(Received March 25, 1997)

\begin{abstract}
Poly(L-lysine) is a polypeptide having a bulky hydrophobic side chain. A systematic study of the full vibrational dynamics, including phonon dispersion, for the $\alpha$-helical form of this biopolymer has been reported using Wilson's $G F$ matrix method as modified by Higgs for an infinite polymeric chain. The calculated frequencies explain well the IR and Raman spectra. A comparison of the amide modes with other $\alpha$-helical polypeptides is reported here. Spectral frequencies have been obtained for the $\mathrm{N}$-deuterated species to check the validity of force field and correctness of assignments. Heat capacity has also been calculated from dispersion curves via density-of-states using Debye relation in the temperature range 50 - $500 \mathrm{~K}$. The calculated values are found to be in close agreement with the recent experimental data of Roles et al. [Biopolymers, 33, 753 (1993)].
\end{abstract}

KEY WORDS Vibrational Dynamics / Phonon Dispersion / Density-of-States / Heat Capacity /

Proteins are considered linear polymers of amino acids with a polypeptide backbone and occasional disulfide cross-linking. Synthetic linear polyamino acids are therefore used as model compounds for the study of more complex proteins. Poly(L-lysine) (Plys) is a very attractive model for studying the protein conformations because it can form extensively any of the three most common secondary structures, namely $\alpha$-helix, antiparallel $\beta$-sheet and the so called random coil, depending on $\mathrm{pH}$ and temperature of the medium and the relative humidity of the atmosphere. In the solid state, it is mainly in $\alpha$-helical form. ${ }^{1}$ Plys in aqueous solution, below $\mathrm{pH} 10.5$ in which $\mathrm{NH}_{2}$ group is in a protonated state, exists in random coil conformation. Above this $\mathrm{pH}$ the $\mathrm{NH}_{2}$ group gets deprotonated and acquires $\alpha$-helical conformation below $30^{\circ} \mathrm{C}$ whereas at higher temperature $\beta$-sheet conformation is preferred over $\alpha$-helix. ${ }^{2,3}$ The $\alpha$-helix conformation is present at relative humidity of $76 \%$ and up while the $\beta$-sheet conformation is observed between $33 \%$ and $76 \%$ relative humidity. Crystals in $\alpha$-helical conformation are assumed to be hexagonally packed while in $\beta$-sheet they form an orthorhombic unit cell. ${ }^{4}$

The free energy difference between the $\alpha$-helix and $\beta$-sheet conformations is very small. ${ }^{5}$ The addition of solvents like methanol to neutral solutions of Plys favors helix formation. ${ }^{6}$ In the presence of specific ions like $\mathrm{ClO}_{4}^{-}, \mathrm{SCN}^{-}$etc., Plys with protonated side chains acquires the $\alpha$-helical conformation. ${ }^{7-9}$ Carrier et al. ${ }^{10}$ have studied pressure induced changes in the secondary structure of Plys and concluded that in solution both the $\beta$-sheet and unordered polypeptide undergo a reversible, pressure induced conformational change to $\alpha$-helix. The conversion occurs at a much higher pressure from the unordered conformer $(9 \mathrm{kbar})$ than from the $\beta$-sheets ( 2 kbar). An increase of polylysine concentration at high $\mathrm{pH}$ slows down these conformational transformations.

Various techniques such as X-ray diffraction, Raman and infra red (IR) spectroscopy are used to determine the structure of a polymer. The Raman spectra in solid state as well as in aqueous solution have been reported

\footnotetext{
† To whom all correspondence should be addressed.
}

by Koenig and Sutton ${ }^{1}$ and by $\mathrm{Yu}$ et $a .^{3}{ }^{3}$ Painter and Koenig ${ }^{8}$ have also reported both the infra red and Raman spectra. We have recorded the IR spectra of Plys (solid state) in the range $4000-450 \mathrm{~cm}^{-1}$ on Perkin-Elmer 1800 spectrophotometer. The study of dispersion curves is necessary to appreciate the origin of both symmetry dependent and symmetry independent spectral features. Dispersion curves provide information on the extent of coupling along the chain together with an understanding of the dependence of the frequency of a given mode upon the sequence length of the ordered conformation. The regions of high density-of-states, which appear in all these techniques and play important roles in thermodynamical behavior, are also dependent on the profile of dispersion curves. Thus, study of dispersion curves is very important to understand fully the conformation of a polymer at the microscopic level. To the best of our knowledge no work has been reported so far on the normal mode analysis and phonon dispersion of Plys. We report here a complete normal mode analysis, phonon dispersion, density-of-states and heat capacity in the temperature range $50-500 \mathrm{~K}$. The calculated values are compared with the recent experimental data reported by Roles et $a l .{ }^{11}$ and the agreement between the two is found to be reasonably good.

Our calculations are supported by the expected shift obtained in the amide modes of Plys on $N$-deuteration of the sample. This also confirms the correctness of assignments and validity of the force field (Urey-Bradley) used in our calculations.

\section{THEORY}

\section{Calculation of Normal Mode Frequencies}

The calculation of normal mode frequencies has been carried out according to Wilson's $G F$ matrix method ${ }^{12}$ as modified by Higgs ${ }^{13}$ for an infinite chain. The Wilson's $G F$ matrix method consists of writing the inverse kinetic energy matrix $G$ and potential energy matrix $F$ in internal coordinates $R$. In the case of infinite isolated helical polymer, there is an infinite number of internal coordinates which lead to $G$ and $F$ matrices of infinite 
order. Due to the screw symmetry of the polymer a transformation similar to that given by Born and Von Karman can be performed which reduces the infinite problem to finite dimensions. The transformation consists of defining a set of symmetry coordinates

$$
S(\delta)=\sum_{s=-\infty}^{\infty} R^{n} \exp (i s \delta)
$$

where $\delta$ is the vibrational phase difference between the corresponding modes of the adjacent residue units.

The elements of the $G(\delta)$ and $F(\delta)$ matrices have the form:

$$
\begin{aligned}
& G_{i k}(\delta)=\sum_{s=-\infty}^{\infty} G_{i k}^{s} \exp (i s \delta) \\
& F_{i k}(\delta)=\sum_{s=-\infty}^{\infty} F_{i k}^{s} \exp (i s \delta)
\end{aligned}
$$

The vibrational secular equation which gives normal mode frequencies and dispersion as a function of phase angle has the form:

$$
[G(\delta) F(\delta)-\lambda(\delta) I=0 \quad 0 \leq \delta \leq \pi
$$

The vibrational frequencies $v(\delta)$ (in $\mathrm{cm}^{-1}$ ) are related to eigen values $\lambda(\delta)$ by the following relation:

$$
\lambda(\delta)=4 \pi^{2} c^{2} v^{2}(\delta)
$$

For any given phase difference $\delta$ (other than 0 or $\pi$ ), the $G(\delta)$ and $F(\delta)$ matrices are complex. To avoid the difficulties involved in handling complex numbers, methods have been devised to transform the complex matrices into equivalent real matrices by constructing suitable linear combinations of coordinates. One method of transforming a complex matrix to its real matrix equivalent is through a similarity transformation. It can be shown that any complex matrix $H=M+i N$ can be replaced by real ones:

$$
\left|\begin{array}{cc}
M & -N \\
N & M
\end{array}\right|
$$

In the present case, we write $G(\delta)=G^{R}(\delta)+i G^{I}(\delta)$ and $F(\delta)=F^{R}(\delta)+i F^{I}(\delta)$, where $G^{R}(\delta), F^{R}(\delta), G^{I}(\delta), F^{I}(\delta)$ are the real and imaginary parts of $G(\delta)$ and $F(\delta)$. The product $H(\delta)=G(\delta) F(\delta)$ becomes:

$$
\begin{aligned}
H(\delta) & =\left|\begin{array}{cc}
G^{R}(\delta) & -G^{I}(\delta) \\
G^{I}(\delta) & G^{R}(\delta)
\end{array}\right| \times\left|\begin{array}{cc}
F^{R}(\delta) & -F^{I}(\delta) \\
F^{I}(\delta) & F^{R}(\delta)
\end{array}\right| \\
& =\left|\begin{array}{cc}
H^{R}(\delta) & -H^{I}(\delta) \\
H^{I}(\delta) & H^{R}(\delta)
\end{array}\right|
\end{aligned}
$$

where

$$
\begin{aligned}
& H^{R}(\delta)=G^{R}(\delta) F^{R}(\delta)-G^{I}(\delta) F^{I}(\delta) \\
& H^{I}(\delta)=G^{R}(\delta) F^{I}(\delta)+G^{I}(\delta) F^{R}(\delta)
\end{aligned}
$$

The matrix $H(\delta)$ now has the dimensions $2 N \times 2 N$. The eigenvalues, therefore, occur in pairs of equal values. The difficulty of dealing with complex numbers is thus avoided.

\section{Force Constant Evaluation}

The force constants have been obtained by the least square fitting. To obtain the 'best fit' with the observed frequencies the following procedure was adopted. Initially approximate force constants are transferred from poly(L-leucine $)^{14}$ and other hydrocarbons having similar groups. Thus starting with the approximate $F$ matrix $F_{0}$ and the observed frequencies $\lambda_{\text {obs }}$ (related through a constant), one can solve the secular matrix equation

$$
G F_{0} L_{0}=L_{0} \lambda_{0}
$$

Let $\Delta \lambda i=\lambda i_{\mathrm{obs}}-\lambda i_{0}$ in the above equation. It can be shown that in the first order approximation

$$
\Delta \lambda=J \Delta F
$$

where $J$ is computed from $L_{0}$. We wish to compute the corrections to $F_{0}$ so that the errors $\overline{\Delta \lambda}$ are minimized. We use the theory of least squares and calculate

$$
J^{\prime} P \overline{\Delta \lambda}=\left(J^{\prime} P J\right) \overline{\Delta F}
$$

where $P$ is a weighting matrix and $J^{\prime}$ is the transpose of $J$. The solution to this equation is obtained by inverting $\left(J^{\prime} P J\right)$ to give

$$
\overline{\Delta F}=\left(J^{\prime} P J\right)^{-1} J^{\prime} P \overline{\Delta \lambda}
$$

If the number of frequencies is greater than the number of $F$ matrix elements, the matrix $J^{\prime} P J$ should be non singular and we obtain the corrections $\Delta F$ which will minimize the sum of the weighted squares of the residuals. If the corrections $\Delta F$ are fairly large, the linear relation between force constant and frequency term in the matrix equation 1 breaks down. In such a situation, further refinement using higher order terms in the Taylor's series expansion of $\Delta \lambda_{i}$ is needed. This procedure has been developed by King and others. ${ }^{15}$

\section{Calculation of Specific Heat}

Dispersion curves, depicting the microscopic behavior of the system, can be used to calculate macroscopic parameters of the system such as specific heat. The state density distribution function $g(v)$, giving the number of energy states in a unit interval of energy, for one dimensional system is given by

$$
g(v)=\left.\sum_{j}\left(\partial v_{j} / \partial \delta\right)^{-1}\right|_{v_{j}(\delta)=v}
$$

The summation is over all branches $(j)$ of normal modes. Considering the system as an assembly of harmonic oscillators, the distribution function $g(v)$ is equivalent to a partition function. The heat capacity at constant volume is then given by Debye's relation

$$
C_{\mathrm{v}}=\sum_{j} g\left(v_{j}\right) k N_{A}\left(h v_{j} / k T\right)^{2} \frac{\exp \left(h v_{j} / k T\right)}{\left[\exp \left(h v_{j} / k T\right)-1\right]^{2}}
$$

with

$$
\sum_{j} g\left(v_{j}\right) \mathrm{d} v_{j}=1
$$

The constant volume heat capacity $C_{\mathrm{v}}$, given by eq 2 is converted into constant pressure heat capacity $C_{\mathrm{p}}$ using the Nernst-Lindemann approximation ${ }^{16}$ : 


$$
C_{\mathrm{p}}-C_{\mathrm{v}}=3 R A_{0}\left(C_{\mathrm{p}}{ }^{2} T / C_{\mathrm{v}} T_{\mathrm{m}}{ }^{0}\right)
$$

where $A_{0}$ is a constant of universal value $\left(3.9 \times 10^{-3} \mathrm{~K}\right.$ $\mathrm{mol} \mathrm{J^{-1 }}$ ) and $T_{\mathrm{m}}{ }^{0}$ is the estimated equilibrium melting temperature taken to be $573 \mathrm{~K}$.

\section{RESULTS AND DISCUSSION}

Plys has 21 atoms per residue unit (as shown in Figure 1) which give rise to 63 dispersion curves. The geometry of the main chain and side chain was obtained by molecular modelling techniques and minimization of conformational energy. The vibrational frequencies are calculated for the values of $\delta$ varying from 0 to $\pi$ in steps of $0.05 \pi$. The modes corresponding to $\delta=0$ and $\delta=\psi$ are both Raman and IR active while the modes corresponding to $\delta=2 \psi$ are only Raman active. The helix angle $\psi$ is the angle of rotation about the helix axis which separates the adjacent units in the chain. For $\alpha$-helical Plys helix angle is $5 \pi / 9$. The structural parameters used are given in Table I. Initially the force constants are transferred from poly(L-leucine) ${ }^{14}$ and the calculated frequencies at $\delta=0$ and $\delta=5 \pi / 9$ are compared with the observed ones. The force constants which gave the best fit to the experimental data are given in Table II. Since the spectra in the low frequency region are not available, exact fitting of the force constants related to this

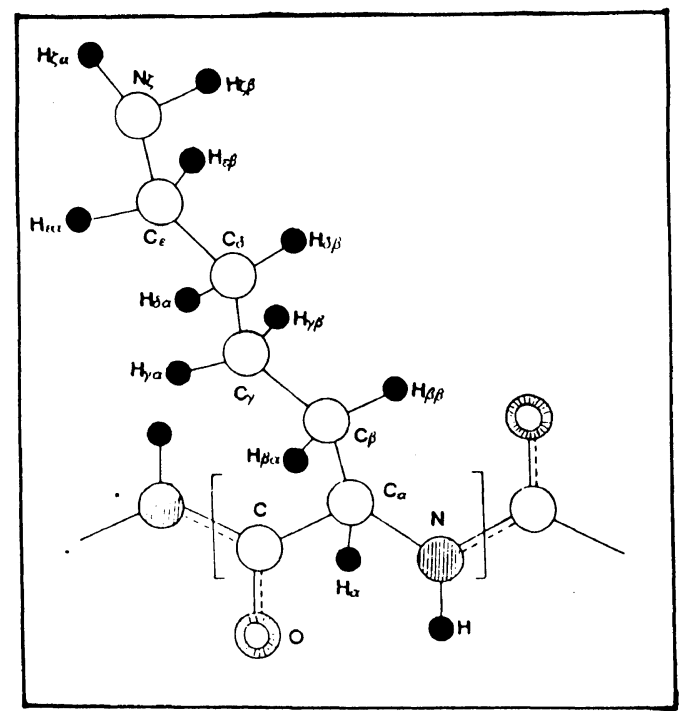

Figure 1. Chemical repeat unit of poly(L-lysine).

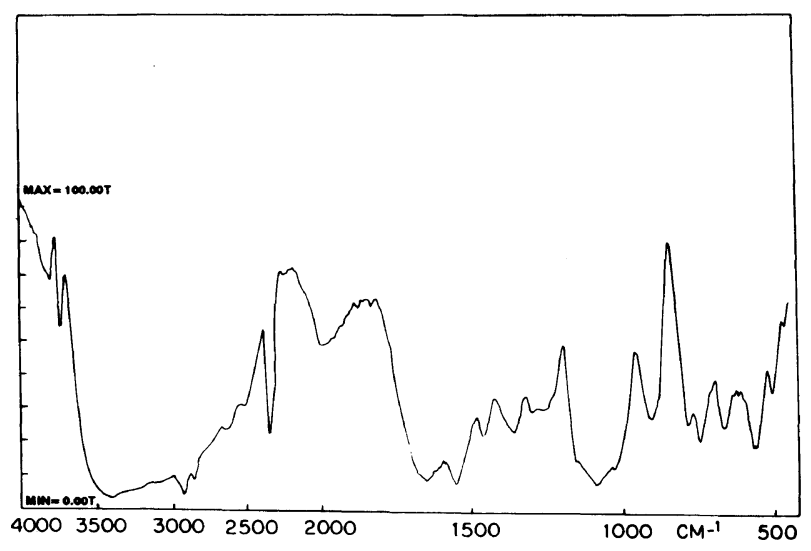

Figure 2. F.T.I.R. spectra of poly(L-lysine) $\left(4000-450 \mathrm{~cm}^{-1}\right)$. region could not be carried out. However, in the near infrared region, the calculated frequencies depend on both bonded as well as non-bonded interactions and if they generate the "best" values in this region then in the low frequency region also, where non-bonded interactions play a dominant role, the calculated frequencies should be reasonably close to the observed ones. Therefore, the force constants related with the low frequency vibrational modes are assumed as given in Table II, although no data necessary for checking the reasonableness can be obtained now. Since the modes above 1345

Table I. Structural parameters of $\alpha$-poly(L-lysine $)^{\mathrm{a}}$

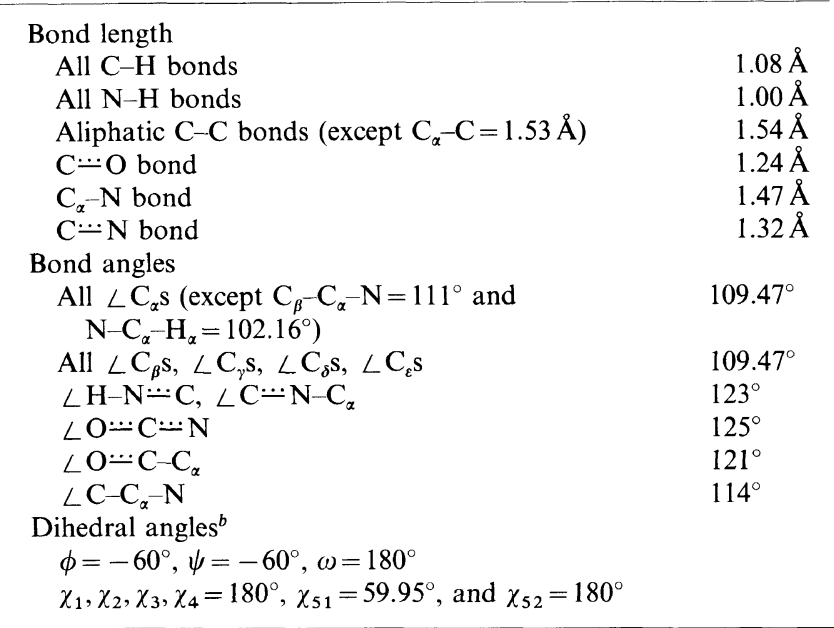

${ }^{a}$ See Figure 1. ${ }^{b}$ Obtained from molecular modelling and conformational energy calculations.

Table II. Internal coordinates and Urey-Bradley force constants ( $\left.\mathrm{md} \AA^{-1}\right)^{\mathrm{a}}$

\begin{tabular}{|c|c|c|c|}
\hline$v(\mathrm{C} \rightleftharpoons \mathrm{O})$ & 7.900 & $\phi\left(\mathrm{C}-\mathrm{N}-\mathrm{C}_{\alpha}\right)$ & $0.530(0.35)$ \\
\hline$v(\mathbf{C} \cdots \mathbf{N})$ & 6.500 & $\phi(\mathrm{C}-\mathrm{N}-\mathrm{H})$ & $0.300(0.65)$ \\
\hline$v(\mathrm{~N}-\mathrm{H})$ & 5.306 & $\phi\left(\mathrm{H}-\mathrm{N}-\mathrm{C}_{\alpha}\right)$ & $0.300(0.60)$ \\
\hline$v\left(\mathrm{~N}-\mathrm{C}_{\alpha}\right)$ & 2.700 & $\phi\left(\mathrm{N}-\mathrm{C}_{\alpha}-\mathrm{H}_{\alpha}\right)$ & $0.313(0.80)$ \\
\hline$v\left(\mathrm{C}_{\alpha}-\mathrm{H}_{\alpha}\right)$ & 4.320 & $\phi\left(\mathrm{N}-\mathrm{C}_{\alpha}-\mathrm{C}\right)$ & $0.130(0.50)$ \\
\hline$v\left(\mathrm{C}_{\alpha}-\mathrm{C}_{\beta}\right)$ & 2.900 & $\phi\left(\mathrm{H}_{\alpha}-\mathrm{C}_{\alpha}-\mathrm{C}\right)$ & $0.407(0.20)$ \\
\hline$v\left(\mathrm{C}_{\alpha}-\mathrm{C}\right)$ & 2.900 & $\phi\left(\mathrm{N}-\mathrm{C}_{\alpha}-\mathrm{C}_{\beta}\right)$ & $0.450(0.50)$ \\
\hline$v\left(\mathrm{C}_{\beta}-\mathrm{H}_{\beta \beta}\right)$ & 4.225 & $\phi\left(\mathrm{H}_{\alpha}-\mathrm{C}_{\alpha}-\mathrm{C}_{\beta}\right)$ & $0.417(0.21)$ \\
\hline$v\left(\mathrm{C}_{\beta}-\mathrm{C}_{\gamma}\right)$ & 2.750 & $\phi\left(\mathrm{C}-\mathrm{C}_{\alpha}-\mathrm{C}_{\beta}\right)$ & $0.520(0.18)$ \\
\hline$v\left(\mathrm{C}_{\gamma}-\mathrm{H}_{\gamma \beta}\right)$ & 4.225 & $\phi\left(\mathrm{C}_{\alpha}-\mathrm{C}_{\beta}-\mathrm{H}_{\beta \beta}\right)$ & $0.370(0.20)$ \\
\hline$v\left(\mathrm{C}_{\gamma}-\mathrm{C}_{\delta}\right)$ & 2.650 & $\phi\left(\mathrm{C}_{\alpha}-\mathrm{C}_{\beta}-\mathrm{C}_{\gamma}\right)$ & $0.550(0.18)$ \\
\hline$v\left(\mathrm{C}_{\delta}-\mathrm{H}_{\delta \beta}\right)$ & 4.220 & $\phi\left(\mathrm{H}_{\beta \beta}-\mathrm{C}_{\beta}-\mathrm{C}_{\gamma}\right)$ & $0.360(0.20)$ \\
\hline$v\left(\mathrm{C}_{\delta}-\mathrm{H}_{\delta \alpha}\right)$ & 4.235 & $\phi\left(\mathrm{H}_{\beta \beta}-\mathrm{C}_{\beta}-\mathrm{H}_{\beta \alpha}\right)$ & $0.410(0.32)$ \\
\hline$v\left(\mathrm{C}_{\delta}-\mathrm{C}_{\varepsilon}\right)$ & 3.230 & $\phi\left(\mathrm{C}_{\beta}-\mathrm{C}_{\gamma}-\mathrm{H}_{\gamma \beta}\right)$ & $0.348(0.20)$ \\
\hline$v\left(\mathrm{C}_{\varepsilon}-\mathrm{H}_{\varepsilon \beta}\right)$ & 4.255 & $\phi\left(\mathrm{C}_{\beta}-\mathrm{C}_{\gamma}-\mathrm{C}_{\delta}\right)$ & $0.560(0.18)$ \\
\hline$v\left(\mathrm{C}_{\varepsilon}-\mathrm{N}_{\xi}\right)$ & 2.100 & $\phi\left(\mathrm{H}_{\gamma \beta}-\mathrm{C}_{\gamma}-\mathrm{H}_{\gamma \alpha}\right)$ & $0.405(0.32)$ \\
\hline \multirow[t]{2}{*}{$v\left(\mathrm{~N}_{\xi}-\mathrm{H}_{\xi \beta}\right)$} & 5.900 & $\phi\left(\mathrm{H}_{\gamma \beta}-\mathrm{C}_{\gamma}-\mathrm{C}_{\delta}\right)$ & $0.348(0.20)$ \\
\hline & & $\phi\left(\mathrm{C}_{\gamma}-\mathrm{C}_{\delta}-\mathrm{H}_{\delta \beta}\right)$ & $0.380(0.20)$ \\
\hline$\omega(\mathrm{N}-\mathrm{H})$ & 0.120 & $\phi\left(\mathrm{C}_{\gamma}-\mathrm{C}_{\delta}-\mathrm{C}_{\varepsilon}\right)$ & $0.550(0.18)$ \\
\hline$\omega(\mathrm{O} \cdots \mathrm{C})$ & 0.560 & $\phi\left(\mathrm{H}_{\delta \beta}-\mathrm{C}_{\delta}-\mathrm{H}_{\delta \alpha}\right)$ & $0.402(0.32)$ \\
\hline \multirow[t]{2}{*}{$\omega\left(\mathrm{H}_{\xi \beta}-\mathrm{N}_{\xi}\right)$} & 0.017 & $\phi\left(\mathrm{H}_{\delta \beta}-\mathrm{C}_{\delta}-\mathrm{C}_{\varepsilon}\right)$ & $0.335(0.20)$ \\
\hline & & $\phi\left(\mathrm{C}_{\delta}-\mathrm{C}_{\varepsilon}-\mathrm{H}_{\varepsilon \beta}\right)$ & $0.350(0.20)$ \\
\hline$\tau\left(\mathrm{N}-\mathrm{C}_{\alpha}\right)$ & 0.010 & $\phi\left(\mathrm{C}_{\delta}-\mathrm{C}_{\varepsilon}-\mathrm{N}_{\xi}\right)$ & $0.105(0.39)$ \\
\hline$\tau\left(\mathrm{C}_{\alpha}-\mathrm{C}_{\beta}\right)$ & 0.010 & $\phi\left(\mathrm{H}_{\varepsilon \beta}-\mathrm{C}_{\varepsilon}-\mathrm{H}_{\varepsilon \alpha}\right)$ & $0.403(0.25)$ \\
\hline$\tau\left(\mathrm{C}_{\boldsymbol{\beta}}-\mathrm{C}_{\gamma}\right)$ & 0.025 & $\phi\left(\mathrm{H}_{\varepsilon \beta}-\mathrm{C}_{\varepsilon}-\mathrm{N}_{\xi}\right)$ & $0.280(0.80)$ \\
\hline$\tau\left(\mathrm{C}_{\gamma}-\mathrm{C}_{\delta}\right)$ & 0.0185 & $\phi\left(\mathrm{C}_{\varepsilon}-\mathrm{N}_{\xi}-\mathrm{H}_{\xi \beta}\right)$ & $0.615(0.60)$ \\
\hline$\tau\left(\mathrm{C}_{\delta}-\mathrm{C}_{\varepsilon}\right)$ & 0.0185 & $\phi\left(\mathrm{H}_{\xi \beta}-\mathrm{N}_{\xi}-\mathrm{H}_{\xi \alpha}\right)$ & $0.285(0.26)$ \\
\hline$\tau\left(\mathrm{C}_{\varepsilon}-\mathrm{N}_{\xi}\right)$ & 0.010 & $\phi\left(\mathrm{C}_{\alpha}-\mathrm{C}-\mathrm{N}\right)$ & $0.290(0.60)$ \\
\hline$\tau\left(\mathrm{C}_{\alpha}-\mathrm{C}\right)$ & 0.025 & $\phi\left(\mathrm{C}_{\alpha}-\mathrm{C} \cdots \mathrm{O}\right)$ & $0.250(0.60)$ \\
\hline$\tau(\mathrm{C}-\mathrm{O} N)$ & 0.045 & $\phi(\mathrm{O} \cdots \mathrm{C} \cdots \mathrm{N})$ & $0.900(0.90)$ \\
\hline
\end{tabular}

${ }^{\mathrm{a}} v, \phi, \omega, \tau$ denote stretch, angle bend, wag, and torsion, respectively. Stretching force-constants between the nonbonded atoms in each angular triplet (gem configuration) are given in parentheses. 

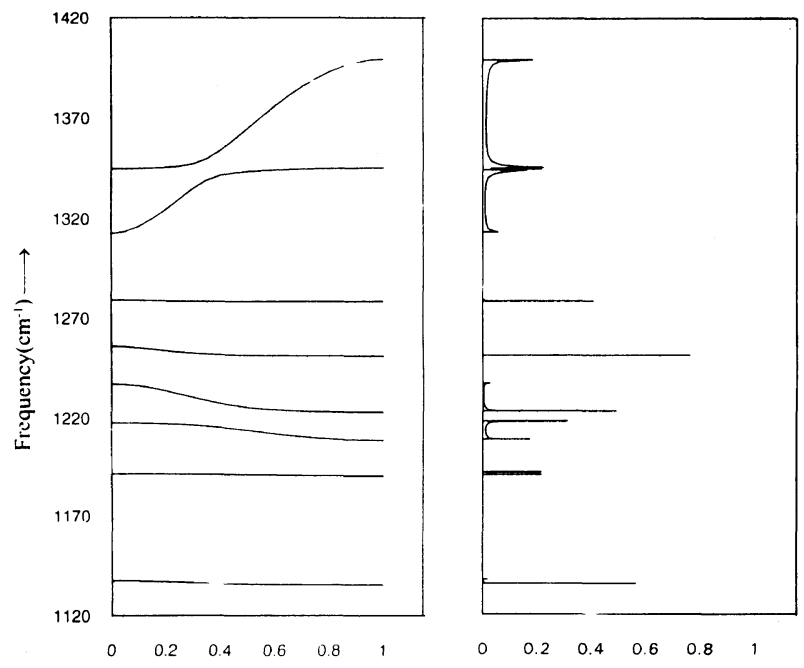

Phase Factor $(\dot{\delta} / \pi) \longrightarrow$

Figure 3. (a) Dispersion curves of poly(L-lysine) $\left(1420-1120 \mathrm{~cm}^{-1}\right)$. (b) Density-of-states $g(v)\left(1420-1120 \mathrm{~cm}^{-1}\right)$.
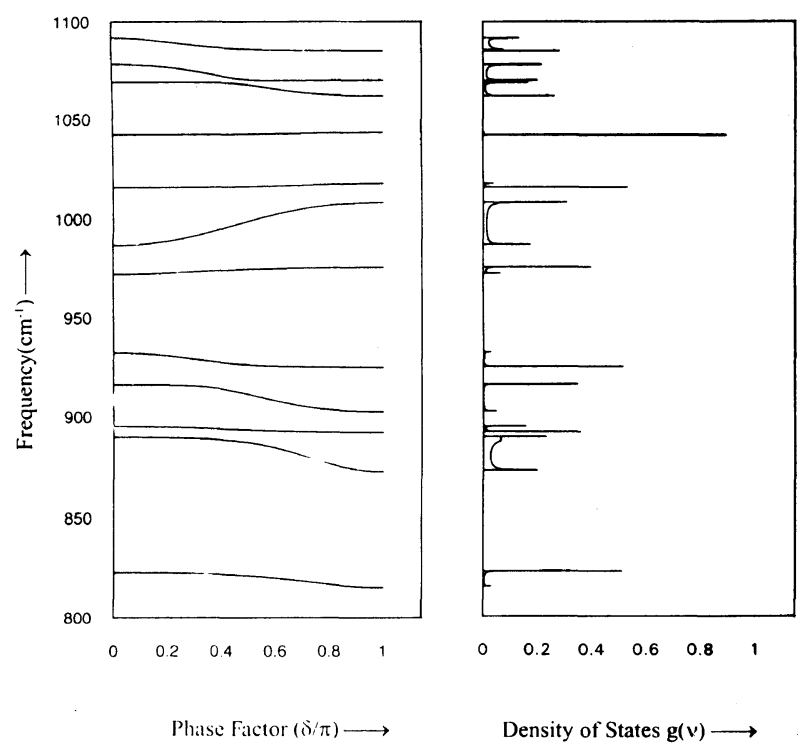

Figure 4. (a) Dispersion curves of poly(L-lysine) $\left(1100-800 \mathrm{~cm}^{-1}\right)$. (b) Density-of-states $g(v)\left(1100-800 \mathrm{~cm}^{-1}\right)$.

$\mathrm{cm}^{-1}$ (except amide I and amide II) are nondispersive, only the modes below this are shown in Figures 3a, 4a, $5 \mathrm{a}$, and $6 \mathrm{a}$. The two lowest lying branches $(\delta=0$ and $\delta=5 \pi / 9, v=0$ ) are the four acoustic modes corresponding to rotation about helix axis and three translations, one parallel and two perpendicular to the helix axis.

The assignment of modes is based not only on the potential energy distribution but also on the line intensity, line profile, second derivative spectra and presence/ absence of modes in molecules having atoms placed in the same environment. No calculation of the absolute intensity or profile of the spectral lines has been done. However, the relative intensity and profiles of absorption bands have been used in the assignment of modes, in particular for the amide and skeleton modes. The modes are discussed under three separate heads namely back bone modes, side chain modes, and mix modes.
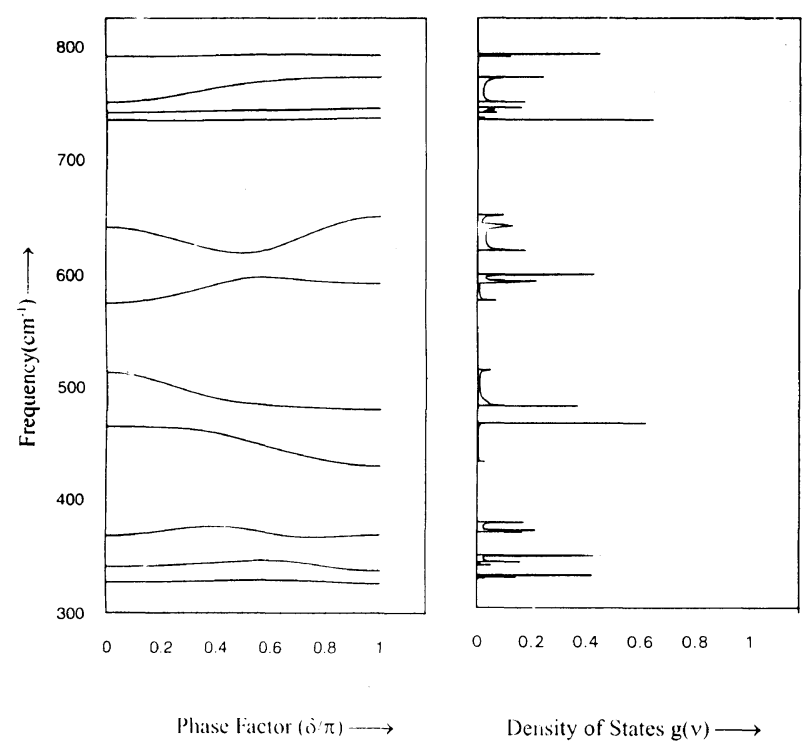

Figure 5. (a) Dispersion curves of poly (L-lysine) $\left(800-300 \mathrm{~cm}^{-1}\right)$. (b) Density-of-states $g(v)\left(800-300 \mathrm{~cm}^{-1}\right)$.
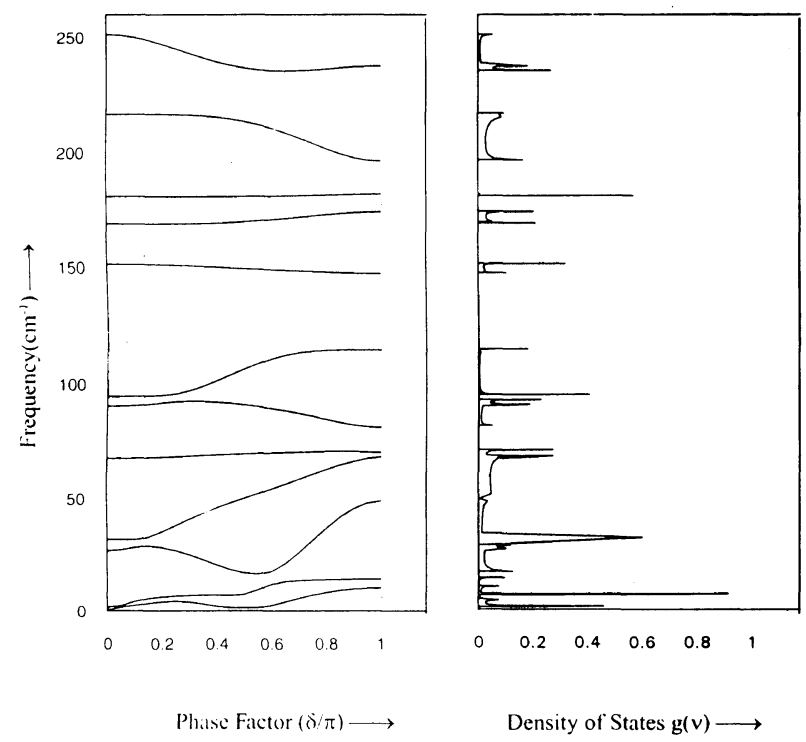

Figure 6. (a) Dispersion curves of poly(L-lysine) $\left(250-00 \mathrm{~cm}^{-1}\right)$. (b) Density-of-states $g(v)\left(250-00 \mathrm{~cm}^{-1}\right)$.

\section{Back Bone Modes}

The modes involving the motion of the atoms of main chain $\left(-\mathrm{C}-\mathrm{C}_{\alpha}-\mathrm{N}-\right)$ are called as back bone modes. These modes along with their assignments at both $\delta=0$ and $\delta=5 \pi / 9$ are given in Table III. Most of these modes are the amide modes. A comparison of amide modes of Plys with other $\alpha$-helical polypeptides is shown in Table IV. It is clear that the frequencies of all these modes (except amide IV and amide VI) agree well with other $\alpha$-helical polypeptides.

The amide A mode due to $\mathrm{N}-\mathrm{H}$ stretching vibration is assigned at $3293 \mathrm{~cm}^{-1}$ and is the same as that of $\alpha$-poly(L-valine) ${ }^{17}$ and $\alpha$-poly(L-alanine). ${ }^{18}$ The amide I mode which has dominantly $\mathrm{C} \cdots \mathrm{O}$ stretch contribution is calculated at $1653 \mathrm{~cm}^{-1}$ at $\delta=0$. At $\delta=5 \pi / 9$ this mode goes to $1679 \mathrm{~cm}^{-1}$ thereby showing a dispersion of 26 wavenumbers. On increasing the $\delta$ values the percentage 
Table III. Back-bone modes ${ }^{\mathrm{a}}$

\begin{tabular}{|c|c|c|c|c|c|}
\hline \multicolumn{2}{|c|}{ Freq. $/ \mathrm{cm}^{-1}$} & \multirow{2}{*}{ Assigments ( $\%$ P.E.D. at $\delta=0.00)$} & \multicolumn{2}{|c|}{ Freq. $/ \mathrm{cm}^{-1}$} & \multirow{2}{*}{ Assignments ( $\%$ P.E.D. at $\delta=0.56 \pi$ ) } \\
\hline Cacld & Obsd & & Calcd & Obsd & \\
\hline 3293 & 3293 & $v[\mathrm{~N}-\mathrm{H}](100)$ & 3293 & 3293 & $v[\mathrm{~N}-\mathrm{H}](100)$ \\
\hline 2969 & 2968 & $v\left[\mathrm{C}_{\alpha}-\mathrm{H}_{\alpha}\right](99)$ & 2969 & 2968 & $v\left[\mathrm{C}_{\alpha}-\mathrm{H}_{\alpha}\right](99)$ \\
\hline 1653 & 1651 & $v[\mathrm{C} \cdots \mathrm{O}](53)+v[\mathrm{C} \cdots \mathrm{N}](34)$ & 1679 & 1666 & $v[\mathrm{C}=\mathrm{O}](46)+v[\mathrm{C}-\mathrm{N}](43)$ \\
\hline 1549 & 1540 & $\begin{array}{l}\phi\left[\mathrm{H}-\mathrm{N}-\mathrm{C}_{\alpha}\right](30)+\phi[\mathrm{C} \because \mathrm{N}-\mathrm{H}](30)+ \\
v[\mathrm{C}-\mathrm{N}](21)+v\left[\mathrm{C}_{\alpha} \mathrm{C}\right](7)\end{array}$ & 1543 & 1540 & $\begin{array}{l}\phi[\mathrm{C}-\mathrm{N}-\mathrm{H}](31)+\phi\left[\mathrm{H}-\mathrm{N}-\mathrm{C}_{\alpha}\right](29)+ \\
v[\mathrm{C}-\mathrm{N}](14)+v\left[\mathrm{C}_{\alpha}-\mathrm{C}\right](8)+v[\mathrm{C}-\mathrm{O}](8)\end{array}$ \\
\hline 641 & 647 & $\begin{array}{l}\omega[\mathrm{N}-\mathrm{H}](32)+\omega[\mathrm{O} \cdots \mathrm{C}](17)+ \\
\phi\left[\mathrm{N}-\mathrm{C}_{\alpha}-\mathrm{C}\right](13)+\tau[\mathrm{C}-\mathrm{N}](10)\end{array}$ & 620 & 614 & $\omega[\mathrm{N}-\mathrm{H}](42)+\tau[\mathrm{C}-\mathrm{N}](20)+\omega[\mathrm{O}-\mathrm{C}](11)$ \\
\hline 575 & $569^{\mathrm{a}}$ & $\begin{array}{l}\tau[\mathrm{C}-\mathrm{N}](17)+\phi\left[\mathrm{C}_{\alpha} \mathrm{C}-\mathrm{N}\right](10)+ \\
\phi[\mathrm{O}-\mathrm{C}-\mathrm{N}](10)+\omega[\mathrm{N}-\mathrm{H}](9)+v\left[\mathrm{C}_{\alpha}-\mathrm{C}\right](7)+ \\
\phi\left[\mathrm{H}_{\alpha}-\mathrm{C}_{\alpha}-\mathrm{C}\right](6)+\phi\left[\mathrm{N}-\mathrm{C}_{\alpha}-\mathrm{C}\right](6)\end{array}$ & 598 & 600 & $\begin{array}{l}\phi[\mathrm{O} \cdots \mathrm{C} \cdots \mathrm{N}](20)+\omega[\mathrm{O} \cdots \mathrm{C}](16)+ \\
v\left[\mathrm{C}_{\alpha}-\mathrm{C}\right](15)+\phi\left[\mathrm{C}_{\alpha}-\mathrm{C}-\mathrm{N}\right](5)\end{array}$ \\
\hline
\end{tabular}

${ }^{\text {a }}$ Frequencies also observed in Raman spectra.

Table IV. Comparision of amide modes of $\alpha$-Plys with other $\alpha$-helical polypeptides ${ }^{\mathrm{a}}$

\begin{tabular}{|c|c|c|c|c|c|c|c|c|c|c|}
\hline \multirow{2}{*}{ Modes } & \multicolumn{2}{|c|}{$\alpha$-Plys } & \multicolumn{2}{|c|}{$\alpha-\mathrm{PLG}$} & \multicolumn{2}{|c|}{$\alpha-P L V$} & \multicolumn{2}{|c|}{$\alpha$-PLA } & \multicolumn{2}{|c|}{$\alpha-P L L$} \\
\hline & $\delta=0$ & $\delta=5 \pi / 9$ & $\delta=0$ & $\delta=5 \pi / 9$ & $\delta=0$ & $\delta=5 \pi / 9$ & $\delta=0$ & $\delta=5 \pi / 9$ & $\delta=0$ & $\delta=5 \pi / 9$ \\
\hline Amide I & 1653 & 1666 & 1652 & 1652 & 1655 & 1650 & 1659 & 1659 & 1657 & 1657 \\
\hline Amide II & 1549 & 1540 & 1510 & 1550 & 1535 & 1520 & 1515 & 1540 & 1546 & 1578 \\
\hline Amide III & 1313 & 1367 & 1283 & 1283 & 1246 & 1253 & 1270 & 1274 & 1299 & 1318 \\
\hline Amide IV & 508 & 600 & - & 670 & 578 & 550 & 525 & 440 & 587 & 633 \\
\hline Amide V & 569 & 614 & 596 & 618 & 622 & 612 & 595 & 610 & 587 & 617 \\
\hline Amide VI & 647 & - & - & - & 691 & 691 & 685 & 656 & 656 & 533 \\
\hline Amide VII & 251 & 236 & 240 & 105 & 125 & 130 & 238 & 190 & 216 & - \\
\hline
\end{tabular}
leucine)

${ }^{a}$ All frequencies are in $\mathrm{cm}^{-1}$. Plys $=\operatorname{poly}(\mathrm{L}-$ lysine $) ; P L G=\operatorname{poly}(\mathrm{L}$-glumatic acid $) ; P L V=\operatorname{poly}(L-v a l i n e) ; P L A=\operatorname{poly}(L-a l a n i n e) ; P L L=\operatorname{poly}(\mathrm{L}-$

contribution of $\mathrm{C}-\mathrm{O}$ stretch decreases from $53 \%$ to $46 \%$ while that of $\mathrm{C} \cdots \mathrm{N}$ stretch increases from $34 \%$ to $43 \%$. The amide II mode $(\mathrm{N}-\mathrm{H}$ in plane bend and $\mathrm{C}-\mathrm{N}$ stretch) also disperses from $1549 \mathrm{~cm}^{-1}$ to $1543 \mathrm{~cm}^{-1}$. This mode is assigned to observed peak at $1540 \mathrm{~cm}^{-1}$. For $\delta>0.7 \pi$ the contribution from $\mathrm{C}=\mathrm{O}$ stretch also starts mixing in this mode.

The observed peak at $647 \mathrm{~cm}^{-1}$ corresponds to calculated frequency $641 \mathrm{~cm}^{-1}$ which has the contribution of $\mathrm{N}-\mathrm{H}$ out-of-plane bend (amide $\mathrm{V}$ ) and $\mathrm{C} \cdots \mathrm{O}$ outof-plane bend (amide VI). With increase in $\delta$ the energy of this mode and contribution of $\mathrm{C}-\mathrm{O}$ out-of-plane bend decreases. At helix angle it becomes $620 \mathrm{~cm}^{-1}$ (assigned to observed peak at $614 \mathrm{~cm}^{-1}$ ) with dominant contribution of amide $\mathrm{V}$. The frequency of this mode compares well with that obtained in other $\alpha$-helical polypeptides (Table IV). At zone centre the mode calculated at $575 \mathrm{~cm}^{-1}$ (mixture of amide $\mathrm{V}$ and amide IV) is assigned to peaks at $569 \mathrm{~cm}^{-1}$ and $564 \mathrm{~cm}^{-1}$ in IR and Raman spectra respectively. At the helix angle this mode becomes a mixture of amide IV and amide VI vibrations and is calculated at $598 \mathrm{~cm}^{-1}$ where it is assigned to observed peak at $600 \mathrm{~cm}^{-1}$. The $\mathrm{C}-\mathrm{H}$ stretching mode calculated at $2969 \mathrm{~cm}^{-1}$ is very close to that of $\alpha$-poly(L-leucine $)^{14}\left(2963 \mathrm{~cm}^{-1}\right)$ and poly(L-aspartic acid) ${ }^{19}$ where it is calculated at $2979 \mathrm{~cm}^{-1}$. The mode is assigned to observed frequency of $2968 \mathrm{~cm}^{-1}$.

\section{Shifting of Modes on $N$-deuteration}

The $N$-deuteration of Plys results in a shift of all these modes which involve the motion of the $\mathrm{N}$-atom of backbone. The frequencies compare well with the Laser
Raman spectra of deuterio derivative reported by Painter and Koenig. ${ }^{8}$ The frequencies of modes before and after $N$-deuteration are given in Table $\mathrm{V}$. The amide I mode calculated at $1648 \mathrm{~cm}^{-1}$ is very close to observed frequency $1646 \mathrm{~cm}^{-1}$. The amide II mode is calculated at $1447 \mathrm{~cm}^{-1}$ resulting in a shift of 102 wavenumbers. This mode is assigned to observed peak at $1459 \mathrm{~cm}^{-1}$. The amide III is calculated at $1104 \mathrm{~cm}^{-1}$ and is assigned to $1129 \mathrm{~cm}^{-1}$. The observed peak at $982 \mathrm{~cm}^{-1}$ corresponds to the mode calculated at $967 \mathrm{~cm}^{-1}$ which has a dominant contribution of side chain $\mathrm{C}-\mathrm{C}$ stretch. A small contribution of $\mathrm{C}-\mathrm{N}-\mathrm{D}$ bending also appears in this mode. Painter and Koenig ${ }^{8}$ propose that this is a new band in Raman spectra of deuterated analogue and is absent in the spectra of undeuterated sample.

\section{Side Chain Modes}

The side chain of Plys consists of four $\mathrm{CH}_{2}$ groups attached to a $\mathrm{NH}_{2}$ group. The modes involving the motion of these atoms are termed as side chain modes and are given in Table VI. Since all these modes are nondispersive, the assignments are given only at $\delta=0$. The $\mathrm{NH}_{2}$ antisymmetric and symmetric stretching modes calculated at $3421 \mathrm{~cm}^{-1}$ and $3362 \mathrm{~cm}^{-1}$ are assigned to observed peaks at $3420 \mathrm{~cm}^{-1}$ and $3362 \mathrm{~cm}^{-1}$, respectively.

The scissoring modes of methylene groups at $\beta, \gamma$, and $\delta$ positions are calculated at 1468,1452 , and $1461 \mathrm{~cm}^{-1}$ and are assigned to observed peaks at 1470, 1454, and $1463 \mathrm{~cm}^{-1}$, respectively. The calculated frequency $1460 \mathrm{~cm}^{-1}$ (assigned to observed peak at $1463 \mathrm{~cm}^{-1}$ ) involves the scissoring motion of $\mathrm{CH}_{2}$ group at $\varepsilon$ position. 
Table V. Modes shifting on $N$-deuteration

\begin{tabular}{|c|c|c|}
\hline \multicolumn{2}{|c|}{ Freq. $/ \mathrm{cm}^{-1}$} & \multirow{2}{*}{ Assignments ( $\%$ P.E.D. at $\delta=0.00)$ on $N$-Deuteration } \\
\hline Calcd & Obsd & \\
\hline 2402 & - & $v[\mathrm{~N}-\mathrm{D}](98)$ \\
\hline 1648 & 1646 & $v[\mathrm{C}-\mathrm{O}](51)+v[\mathrm{C}-\mathrm{N}](38)$ \\
\hline 1447 & 1459 & $\begin{array}{l}v[\mathrm{C}-\mathrm{N}](31)+v\left[\mathrm{C}_{\alpha}-\mathrm{C}\right](20)+v[\mathrm{C}-\mathrm{O}](13)+ \\
\phi[\mathrm{O}-\mathrm{C}-\mathrm{N}](10)+\phi[\mathrm{C}-\mathrm{N}-\mathrm{D}](9)+ \\
\phi\left[\mathrm{D}-\mathrm{N}-\mathrm{C}_{\alpha}\right](6)\end{array}$ \\
\hline 1342 & - & $\phi\left[\mathrm{N}-\mathrm{C}_{\alpha}-\mathrm{H}_{\alpha}\right](65)+\phi\left[\mathrm{H}_{\alpha}-\mathrm{C}_{\alpha}-\mathrm{C}_{\beta}\right](13)+v\left[\mathrm{C}_{\alpha}-\mathrm{C}_{\beta}\right](5)$ \\
\hline 1104 & 1129 & $\begin{array}{l}v\left[\mathrm{~N}-\mathrm{C}_{\alpha}\right](19)+\phi\left[\mathrm{C}_{\alpha}-\mathrm{C}_{\beta}-\mathrm{H}_{\beta \beta}\right](16)+v\left[\mathrm{C}_{\alpha}-\mathrm{C}\right](16)+ \\
\phi\left[\mathrm{H}_{\beta \beta}-\mathrm{C}_{\beta}-\mathrm{C}_{\gamma}\right](12)+\phi\left[\mathrm{D}-\mathrm{N}-\mathrm{C}_{\alpha}\right](8)+ \\
\phi[\mathrm{C}-\mathrm{N}-\mathrm{D}](7)+\phi\left[\mathrm{H}_{\gamma \beta}-\mathrm{C}_{\gamma}-\mathrm{C}_{\delta}\right](5)\end{array}$ \\
\hline 1036 & 1008 & $\begin{array}{l}\phi\left[\mathrm{D}-\mathrm{N}-\mathrm{C}_{\alpha}\right](21)+\phi\left[\mathrm{H}_{\beta \beta}-\mathrm{C}_{\beta}-\mathrm{C}_{\gamma}\right](13)+ \\
\phi[\mathrm{C}-\mathrm{N}-\mathrm{D}](12)+\phi\left[\mathrm{C}_{\alpha}-\mathrm{C}_{\beta}-\mathrm{H}_{\beta \beta}\right](7)+ \\
\phi\left[\mathrm{H}_{\alpha}-\mathrm{C}_{\alpha}-\mathrm{C}_{\beta}\right](7)\end{array}$ \\
\hline 967 & 982 & $\begin{array}{l}v\left[\mathrm{C}_{\alpha}-\mathrm{C}_{\beta}\right](40)+\phi\left[\mathrm{C}_{\alpha}-\mathrm{C}_{\beta}-\mathrm{H}_{\beta \beta}\right](6)+ \\
\phi[\mathrm{C}-\mathrm{N}-\mathrm{D}](6)+v\left[\mathrm{C}_{\delta}-\mathrm{C}_{\varepsilon}\right](6)+v\left[\mathrm{C}_{\gamma}-\mathrm{C}_{\delta}\right](5)+ \\
\phi\left[\mathrm{H}_{\alpha}-\mathrm{C}_{\alpha}-\mathrm{C}_{\beta}\right](5)\end{array}$ \\
\hline 909 & 904 & $\begin{array}{l}v[\mathrm{C}-\mathrm{O}](8)+v[\mathrm{C}-\mathrm{N}](8)+\phi\left[\mathrm{C}_{\delta}-\mathrm{C}_{\varepsilon}-\mathrm{H}_{\varepsilon \beta}\right](7)+ \\
v\left[\mathrm{C}_{\beta}-\mathrm{C}_{\gamma}\right](7)+\phi[\mathrm{O}-\mathrm{C}-\mathrm{N}](6)+v\left[\mathrm{~N}-\mathrm{C}_{\alpha}\right](6)+ \\
v\left[\mathrm{C}_{\alpha}-\mathrm{C}\right](6)+\phi\left[\mathrm{C}-\mathrm{N}-\mathrm{C}_{\alpha}\right](5)+ \\
\phi\left[\mathrm{H}_{\delta \beta}-\mathrm{C}_{\delta}-\mathrm{C}_{\varepsilon}\right](5)+\phi\left[\mathrm{H}_{\beta \beta}-\mathrm{C}_{\beta}-\mathrm{C}_{\gamma}\right](5)\end{array}$ \\
\hline 725 & - & $\omega[\mathrm{O} \cdots \mathrm{C}](58)+\omega[\mathrm{N}-\mathrm{D}](11)$ \\
\hline 604 & - & $\begin{array}{l}\phi\left[\mathrm{N}-\mathrm{C}_{\alpha}-\mathrm{C}\right](18)+\omega[\mathrm{N}-\mathrm{D}](11)+ \\
\phi[\mathrm{O}-\mathrm{C}-\mathrm{N}](10)+v\left[\mathrm{C}_{\alpha}-\mathrm{C}\right](10)+ \\
\phi\left[\mathrm{C}_{\alpha}-\mathrm{C}-\mathrm{N}\right](9)+\phi\left[\mathrm{H}_{\alpha}-\mathrm{C}_{\alpha}-\mathrm{C}\right](7)\end{array}$ \\
\hline 504 & - & $\begin{array}{l}\phi\left[\mathrm{C}_{\alpha}-\mathrm{C}-\mathrm{O}\right](18)+\phi\left[\mathrm{C}_{\alpha}-\mathrm{C}-\mathrm{N}\right](14)+ \\
\phi\left[\mathrm{N}-\mathrm{C}_{\alpha}-\mathrm{C}_{\beta}\right](13)+\phi\left[\mathrm{C}_{\beta}-\mathrm{C}_{\gamma}-\mathrm{C}_{\delta}\right](12)+ \\
\phi\left[\mathrm{C}_{\delta}-\mathrm{C}_{\varepsilon}-\mathrm{N}_{\xi}\right](7)+v\left[\mathrm{C}_{\alpha}-\mathrm{C}\right](6)\end{array}$ \\
\hline 481 & - & $\omega[\mathrm{N}-\mathrm{D}](50)+\tau[\mathrm{C} \cdots \mathrm{N}](21)$ \\
\hline 238 & - & $\begin{array}{l}\phi\left[\mathrm{N}-\mathrm{C}_{\alpha}-\mathrm{C}\right](14)+\tau\left[\mathrm{C}_{\alpha}-\mathrm{C}\right](13)+\tau[\mathrm{C}-\mathrm{N}](12)+ \\
\phi\left[\mathrm{C}-\mathrm{C}_{\alpha}-\mathrm{C}_{\beta}\right](11)+\tau\left[\mathrm{N}-\mathrm{C}_{\alpha}\right](9)+\tau\left[\mathrm{C}_{\beta}-\mathrm{C}_{\gamma}\right](7)+ \\
\phi\left[\mathrm{C}-\mathrm{N}-\mathrm{C}_{\alpha}\right](6)\end{array}$ \\
\hline
\end{tabular}

The frequency range agrees well with the scissoring modes of poly(L-leucine) $\left(1449 \mathrm{~cm}^{-1}\right),{ }^{14}$ poly(L-glutamic acid) $\left(1451 \mathrm{~cm}^{-1}\right),{ }^{20}$ and poly(L-phenylalanine) (1461 $\left.\mathrm{cm}^{-1}\right){ }^{21}$ The $\mathrm{CH}_{2}$ wagging mode which has also a contribution of $\left(\mathrm{H}_{\varepsilon \beta}-\mathrm{C}_{\varepsilon}-\mathrm{N}_{\zeta}\right)$ bending is calculated at $1192 \mathrm{~cm}^{-1}$ and assigned to observed peak at $1185 \mathrm{~cm}^{-1}$. The range of this mode agrees well with that of poly(L-leucine) $\left(1172 \mathrm{~cm}^{-1}\right)$ and $\operatorname{poly}(\gamma$-benzyl L-glutamate) $\left(1183 \mathrm{~cm}^{-1}\right)$.

The observed peaks at $949 \mathrm{~cm}^{-1}$ in Raman spectra reported by Koenig and Sutton ${ }^{1}$ and $891 \mathrm{~cm}^{-1}$ of IR are assigned to stretches of $\mathrm{C}_{\delta}-\mathrm{C}_{\varepsilon}$ and $\mathrm{C}_{\gamma}-\mathrm{C}_{\delta}$ bonds of side chain respectively. The frequency of $\left(\mathrm{C}_{\delta}-\mathrm{C}_{\varepsilon}\right)$ stretch is higher than that of $\left(\mathrm{C}_{\gamma}-\mathrm{C}_{\delta}\right)$ probably because the $\mathrm{C}_{\varepsilon}$ atom is attached to the $\mathrm{N}_{\zeta}$ atom which is an electron donor and hence is capable of augmenting the binding strength. This is clear from the force constants of these bonds which are $3.23 \mathrm{md} \AA^{-1}$ and $2.65 \mathrm{md}^{-1}$, respectively. The rocking modes of $\mathrm{CH}_{2}$ are at 742 and 735 $\mathrm{cm}^{-1}$ and very close to the observed peak at $738 \mathrm{~cm}^{-1}$. The range of these modes is same as that of other polypeptides having $\mathrm{CH}_{2}$ groups in their side chains.

\section{Mix-Modes}

In most modes below $1345 \mathrm{~cm}^{-1}$ there is a strong coupling of back bone and side chain vibrations. Such modes are termed mix-modes and are given in Table VII along with their assignments at $\delta=0$ and $\delta=0.56 \pi$. The observed peak at $1306 \mathrm{~cm}^{-1}$ in the IR spectra is assigned to the amide III mode calculated at $1313 \mathrm{~cm}^{-1}(\delta=0)$. The observed Raman frequencies $1323 \mathrm{~cm}^{-1}$ by Koenig
Table VI. Side chain modes

\begin{tabular}{|c|c|c|}
\hline \multicolumn{2}{|c|}{ Freq. $/ \mathrm{cm}^{-1}$} & \multirow{2}{*}{ Assigments ( $\%$ P.E.D. at $\delta=0.00)$} \\
\hline Calcd & Obsd & \\
\hline 3421 & 3420 & $v\left[\mathrm{~N}_{\zeta}-\mathrm{H}_{\zeta \beta}\right](100)$ \\
\hline 3362 & 3362 & $v\left[\mathrm{~N}_{\zeta}^{6}-\mathbf{H}_{\xi \beta}\right](100)$ \\
\hline 2997 & 2996 & $v\left[\mathrm{C}_{\varepsilon}-\mathrm{H}_{\varepsilon \beta}\right](99)$ \\
\hline 2965 & 2968 & $v\left[\mathrm{C}_{\varepsilon}-\mathrm{H}_{\varepsilon \beta}\right](100)$ \\
\hline 2930 & 2927 & $\begin{array}{l}v\left[\mathrm{C}_{\gamma}-\mathrm{H}_{\gamma \beta}\right](45)+v\left[\mathrm{C}_{\beta}-\mathrm{H}_{\beta \beta}\right](20)+v\left[\mathrm{C}_{\delta}-\mathrm{H}_{\delta \alpha}\right](18)+ \\
v\left[\mathrm{C}_{\delta}-\mathrm{H}_{\delta \beta}\right](16)\end{array}$ \\
\hline 2926 & 2927 & $v\left[\mathrm{C}_{\beta}-\mathrm{H}_{\beta \beta}\right](50)+v\left[\mathrm{C}_{\delta}-\mathrm{H}_{\delta \alpha}\right](26)+v\left[\mathrm{C}_{\delta}-\mathrm{H}_{\delta \beta}\right](22)$ \\
\hline 2921 & 2927 & $\begin{array}{l}v\left[\mathrm{C}_{\gamma}-\mathrm{H}_{\gamma \beta}\right](53)+v\left[\mathrm{C}_{\beta}-\mathrm{H}_{\beta \beta}\right](29)+v\left[\mathrm{C}_{\delta}-\mathrm{H}_{\delta \beta}\right](10)+ \\
v\left[\mathrm{C}_{\delta}-\mathrm{H}_{\delta \beta}\right](8)\end{array}$ \\
\hline 2868 & 2862 & $\begin{array}{l}v\left[\mathrm{C}_{\gamma}-\mathrm{H}_{\gamma \beta}\right](46)+v\left[\mathrm{C}_{\beta}-\mathrm{H}_{\beta \beta}\right](23)+v\left[\mathrm{C}_{\delta}-\mathrm{H}_{\delta \beta}\right](17)+ \\
v\left[\mathrm{C}_{\delta}-\mathrm{H}_{\delta \alpha}\right](15)\end{array}$ \\
\hline 2866 & 2862 & $v\left[\mathrm{C}_{\beta}-\mathrm{H}_{\beta \beta}\right](50)+v\left[\mathrm{C}_{\delta}-\mathrm{H}_{\delta \beta}\right](26)+v\left[\mathrm{C}_{\delta}-\mathrm{H}_{\delta \alpha}\right](23)$ \\
\hline 2863 & 2862 & $\begin{array}{l}v\left[\mathrm{C}_{\gamma}-\mathrm{H}_{\gamma \beta}\right](53)+v\left[\mathrm{C}_{\beta}-\mathrm{H}_{\beta \beta}\right](27)+v\left[\mathrm{C}_{\delta}-\mathrm{H}_{\delta \beta}\right](10)+ \\
v\left[\mathrm{C}_{\delta}-\mathrm{H}_{\delta \alpha}\right](9)\end{array}$ \\
\hline 1621 & 1618 & $\phi\left[\mathrm{C}_{\varepsilon}-\mathrm{N}_{\zeta}-\mathrm{H}_{\zeta \beta}\right](53)+\phi\left[\mathrm{H}_{\xi \beta}-\mathrm{N}_{\xi}-\mathrm{H}_{\zeta \alpha}\right](43)$ \\
\hline 1468 & $1470^{\mathrm{a}}$ & $\begin{array}{l}\phi\left[\mathrm{H}_{\beta \beta}-\mathrm{C}_{\beta}-\mathrm{H}_{\beta \alpha}\right](51)+\phi\left[\mathrm{H}_{\gamma \beta}-\mathrm{C}_{\gamma}-\mathrm{H}_{\gamma \gamma}\right](23)+ \\
\phi\left[\mathrm{H}_{\delta \beta^{-}}-\mathrm{C}_{\delta}-\mathrm{H}_{\delta \alpha}\right](7)+\phi\left[\mathrm{C}_{\alpha}-\mathrm{C}_{\beta}-\mathrm{H}_{\beta \beta}\right](5)+ \\
\phi\left[\mathrm{H}_{\beta \beta}-\mathrm{C}_{\beta}-\mathrm{C}_{\gamma}\right](5)\end{array}$ \\
\hline 1461 & $1463^{\mathrm{a}}$ & $\begin{array}{l}\phi\left[\mathrm{H}_{\delta \beta}-\mathrm{C}_{\delta}-\mathrm{H}_{\delta \alpha}\right](36)+\phi\left[\mathrm{H}_{\beta \beta}-\mathrm{C}_{\beta}-\mathrm{H}_{\beta \alpha}\right](22)+ \\
\phi\left[\mathrm{H}_{\gamma \beta}-\mathrm{C}_{\gamma}-\mathrm{H}_{\gamma \alpha}\right](12)+\phi\left[\mathrm{H}_{\varepsilon \beta}-\mathrm{C}_{\varepsilon}-\mathrm{H}_{\varepsilon \alpha}\right](7)\end{array}$ \\
\hline 1460 & $1454^{a}$ & 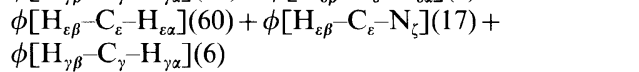 \\
\hline 1452 & $1454^{\mathrm{a}}$ & $\phi\left[\mathrm{H}_{\gamma \beta}-\mathrm{C}_{\gamma}-\mathrm{H}_{\gamma \alpha}\right](40)+\phi\left[\mathrm{H}_{\delta \beta}-\mathrm{C}_{\delta}-\mathrm{H}_{\delta \alpha}\right](34)$ \\
\hline 1400 & $1403^{\mathrm{a}}$ & $\begin{array}{l}\phi\left[\mathrm{C}_{\varepsilon}-\mathrm{N}_{\xi}-\mathrm{H}_{\zeta \beta}\right](59)+\phi\left[\mathrm{H}_{\varepsilon \beta}-\mathrm{C}_{\varepsilon}-\mathrm{N}_{\zeta}\right](20)+ \\
v\left[\mathrm{C}_{\delta}-\mathrm{C}_{\varepsilon}\right](8)+\phi\left[\mathrm{C}_{\delta}-\mathrm{C}_{\varepsilon}-\mathrm{H}_{\varepsilon \beta}\right](6)\end{array}$ \\
\hline 1279 & 1276 & $\begin{array}{l}v\left[\mathrm{C}_{\gamma}-\mathrm{C}_{\delta}\right](12)+v\left[\mathrm{C}_{\beta}-\mathrm{C}_{\gamma}\right](10)+v\left[\mathrm{C}_{\delta}-\mathrm{C}_{\varepsilon}\right](9)+ \\
\phi\left[\mathrm{H}_{\delta \beta}-\mathrm{C}_{\delta}-\mathrm{C}_{\varepsilon}\right](8)+\phi\left[\mathrm{C}_{\gamma}-\mathrm{C}_{\delta}-\mathrm{H}_{\delta \beta}\right](8)+ \\
\phi\left[\mathrm{H}_{\gamma \beta} \mathrm{C}_{\gamma} \mathrm{C}_{\delta}\right](7)+\phi\left[\mathrm{C}_{\beta}-\mathrm{C}_{\gamma}-\mathrm{H}_{\gamma \beta}\right](7)+ \\
\phi\left[\mathrm{C}_{\varepsilon}-\mathrm{N}_{\zeta}-\mathrm{H}_{\zeta \beta}\right](6)+\phi\left[\mathrm{H}_{\beta \beta}-\mathrm{C}_{\beta}-\mathrm{C}_{\gamma}\right](5)+v\left[\mathrm{C}_{\alpha}-\mathrm{C}_{\beta}\right](5)\end{array}$ \\
\hline 1192 & 1185 & $\begin{array}{l}\phi\left[\mathrm{H}_{\varepsilon \beta}-\mathrm{C}_{\varepsilon}-\mathrm{N}_{\zeta}\right](26)+\phi\left[\mathrm{C}_{\delta}-\mathrm{C}_{\varepsilon}-\mathrm{H}_{\varepsilon \beta}\right](22)+ \\
\phi\left[\mathrm{C}_{\varepsilon}-\mathrm{N}_{\zeta}-\mathrm{H}_{\zeta \beta}\right](10)+\phi\left[\mathrm{C}_{\gamma}-\mathrm{C}_{\delta}-\mathrm{H}_{\delta \beta}\right](8)+ \\
\phi\left[\mathrm{H}_{\delta \beta}-\mathrm{C}_{\delta}-\mathrm{C}_{\varepsilon}\right](6)\end{array}$ \\
\hline 1042 & 1047 & $\begin{array}{l}\phi\left[\mathrm{C}_{\gamma}-\mathrm{C}_{\delta}-\mathrm{H}_{\delta \beta}\right](20)+\phi\left[\mathrm{H}_{\beta \beta}-\mathrm{C}_{\beta}-\mathrm{C}_{\gamma}\right](18)+ \\
\phi\left\{\mathrm{H}_{\gamma \beta}-\mathrm{C}_{\gamma}-\mathrm{C}_{\delta}\right](17)+\phi\left[\mathrm{C}_{\beta}-\mathrm{C}_{\gamma}-\mathrm{H}_{\gamma \beta}\right](16)+ \\
\phi\left[\mathrm{C}_{\alpha}-\mathrm{C}_{\beta}-\mathrm{H}_{\beta \beta}\right](13)+\phi\left[\mathrm{H}_{\delta \beta} \mathrm{C}_{\delta} \mathrm{C}_{\varepsilon}\right](10)\end{array}$ \\
\hline 1016 & 1017 & $v\left[\mathrm{C}_{\varepsilon}-\mathrm{N}_{\zeta}\right](68)+\phi\left[\mathrm{C}_{\delta}-\mathrm{C}_{\varepsilon}-\mathrm{N}_{\zeta}\right](6)$ \\
\hline 972 & $949^{\mathrm{a}}$ & $\begin{array}{l}v\left[\mathrm{C}_{\delta}-\mathrm{C}_{\varepsilon}\right](27)+v\left[\mathrm{C}_{\alpha}-\mathrm{C}_{\beta}\right](18)+v\left[\mathrm{C}_{\gamma}-\mathrm{C}_{\delta}\right](14)+ \\
\phi\left[\mathrm{C}_{\delta}-\mathrm{C}_{\varepsilon}-\mathrm{N}_{\zeta}\right](6)\end{array}$ \\
\hline 895 & $891^{\mathrm{a}}$ & $\begin{array}{l}v\left[\mathrm{C}_{\gamma}-\mathrm{C}_{\delta}\right](23)+\phi\left[\mathrm{C}_{\delta}-\mathrm{C}_{\varepsilon}-\mathrm{H}_{\varepsilon \beta}\right](13)+ \\
\phi\left[\mathrm{H}_{\delta \beta}-\mathrm{C}_{\delta}-\mathrm{C}_{\varepsilon}\right](10)+\phi\left[\mathrm{C}_{\gamma}-\mathrm{C}_{\delta}-\mathrm{H}_{\delta \beta}\right](10)+ \\
v\left[\mathrm{C}_{\delta}-\mathrm{C}_{\varepsilon}\right](9)+\phi\left[\mathrm{C}_{\beta}-\mathrm{C}_{\gamma}-\mathrm{H}_{\gamma \beta}\right](7)+v\left[\mathrm{C}_{\beta}-\mathrm{C}_{\gamma}\right](5)+ \\
\phi\left[\mathrm{H}_{\gamma \beta}-\mathrm{C}_{\gamma}-\mathrm{C}_{\delta}\right](5)\end{array}$ \\
\hline 823 & $828^{\mathrm{a}}$ & $\begin{array}{l}\phi\left[\mathrm{H}_{\zeta \beta}-\mathrm{N}_{\zeta}-\mathrm{H}_{\zeta \alpha}\right](16)+\phi\left[\mathrm{C}_{\varepsilon}-\mathrm{N}_{\zeta}-\mathrm{H}_{\zeta \beta}\right](15)+ \\
\phi\left[\mathrm{C}_{\alpha}-\mathrm{C}_{\beta}-\mathrm{H}_{\beta \beta}\right](15)+\phi\left[\mathrm{H}_{\beta \beta}-\mathrm{C}_{\beta}-\mathrm{C}_{\gamma}\right](11)+ \\
\phi\left[\mathrm{H}_{\gamma \beta}-\mathrm{C}_{\gamma}-\mathrm{C}_{\delta}\right](11)+\phi\left[\mathrm{C}_{\delta} \mathrm{C}_{\varepsilon}-\mathrm{H}_{\varepsilon \beta}\right](7)+ \\
\omega\left[\mathrm{H}_{\zeta \beta}-\mathrm{N}_{\zeta}\right](5)\end{array}$ \\
\hline 791 & 796 & $\begin{array}{l}\phi\left[\mathrm{C}_{\varepsilon}-\mathrm{N}_{\zeta}-\mathrm{H}_{\zeta \beta}\right](19)+\phi\left[\mathrm{H}_{\xi \beta}-\mathrm{N}_{\zeta}-\mathrm{H}_{\zeta \alpha}\right](18)+ \\
\phi\left[\mathrm{C}_{\delta}-\mathrm{C}_{\varepsilon}-\mathrm{H}_{\varepsilon \beta}\right](12)+\phi\left[\mathrm{H}_{\beta \beta}-\mathrm{C}_{\beta}-\mathrm{C}_{\gamma}\right](9)+ \\
\phi\left[\mathrm{C}_{\alpha}-\mathrm{C}_{\beta}-\mathrm{H}_{\beta \beta}\right](7)+\phi\left[\mathrm{H}_{\varepsilon \beta}-\mathrm{C}_{\varepsilon}-\mathrm{N}_{\zeta}\right](7)+\omega\left[\mathrm{H}_{\zeta \beta}-\mathrm{N}_{\zeta}\right](6)\end{array}$ \\
\hline 328 & - & $\tau\left[\mathrm{C}_{\varepsilon}-\mathrm{N}_{\varepsilon}\right](75)$ \\
\hline 181 & - & $\begin{array}{l}\tau\left[\mathrm{C}_{\delta}-\mathrm{C}_{\varepsilon}\right](53)+\tau\left[\mathrm{C}_{\gamma}-\mathrm{C}_{\delta}\right](14)+\tau\left[\mathrm{C}_{\beta}-\mathrm{C}_{\gamma}\right](11)+ \\
\tau\left[\mathrm{C}_{\alpha}-\mathrm{C}_{\beta}\right](6)\end{array}$ \\
\hline 68 & - & $\tau\left[\mathrm{C}_{\alpha}-\mathrm{C}_{\beta}\right](33)+\tau\left[\mathrm{C}_{\beta}-\mathrm{C}_{\gamma}\right](28)+\tau\left[\mathrm{C}_{\delta}-\mathrm{C}_{\varepsilon}\right](17)$ \\
\hline
\end{tabular}

${ }^{\mathrm{a}}$ Frequencies are found in Raman spectra also.

and Sutton ${ }^{1}$ and $1311 \mathrm{~cm}^{-1}$ by Chen and Lord $^{22}$ are close to the corresponding IR frequencies. This mode lies well in the range of amide III for $\alpha$-helical polypeptides (Table IV). At the helix angle $(\delta=0.56 \pi)$ amide III mode is calculated at $1372 \mathrm{~cm}^{-1}$ and assigned to observed peak of $1367 \mathrm{~cm}^{-1}$.

The mode calculated at $751 \mathrm{~cm}^{-1}$ at $\delta=0$ has the dominant contribution of wagging of $\mathrm{C}-\mathrm{O}$ and $\mathrm{N}-\mathrm{H}$ groups and is assigned to the peak at $751 \mathrm{~cm}^{-1}$ observed in both IR and Raman spectra. This is a characteristic mode of the $\alpha$-helix and obtained in the same range as 
Table VII. Mix modes

\begin{tabular}{|c|c|c|c|c|c|}
\hline \multicolumn{2}{|c|}{ Freq. $/ \mathrm{cm}^{-1}$} & \multirow{2}{*}{ Assigments ( $\%$ P.E.D. at $\delta=0.00)$} & \multicolumn{2}{|c|}{ Freq. $/ \mathrm{cm}^{-1}$} & \multirow{2}{*}{ Assignments ( $\%$ P.E.D. at $\delta=0.56 \pi)$} \\
\hline Calcd & Obsd & & Calcd & Obsd & \\
\hline 1345 & $1342^{\mathrm{a}}$ & $\phi\left[\mathrm{N}-\mathrm{C}_{\alpha}-\mathrm{H}_{\alpha}\right](64)+\phi\left[\mathrm{H}_{\alpha}-\mathrm{C}_{\alpha}-\mathrm{C}_{\beta}\right](12)$ & 1372 & 1367 & $\begin{array}{l}v\left[\mathrm{C}_{\alpha}-\mathrm{C}\right](26)+\phi\left[\mathrm{H}-\mathrm{N}-\mathrm{C}_{\alpha}\right](15)+v[\mathrm{C}-\mathrm{O}](11)+ \\
v[\mathrm{C}-\mathrm{N}](10)+\phi[\mathrm{C}-\mathrm{N}-\mathrm{H}](8)+ \\
\phi\left[\mathrm{N}-\mathrm{C}_{\alpha}-\mathrm{H}_{\alpha}\right](6)+\phi[\mathrm{O} \cdots \mathrm{C}-\mathrm{N}](6)\end{array}$ \\
\hline 1313 & $1306^{\mathrm{a}}$ & $\begin{array}{l}v[\mathrm{C} \cdots \mathrm{N}](20)+v[\mathrm{C} \cdots \mathrm{O}](19)+v\left[\mathrm{C}_{\alpha}-\mathrm{C}\right](16)+ \\
\phi\left[\mathrm{H}-\mathrm{N}-\mathrm{C}_{\alpha}\right](15)+\phi[\mathrm{O} \cdots \mathrm{C}-\mathrm{N}](10)+ \\
\phi[\mathrm{C}-\mathrm{N}-\mathrm{H}](9)\end{array}$ & 1344 & 1355 & $\begin{array}{l}\phi\left[\mathrm{N}-\mathrm{C}_{\alpha}-\mathrm{H}_{\alpha}\right](63)+\phi\left[\mathrm{H}_{\alpha}-\mathrm{C}_{\alpha}-\mathrm{C}_{\beta}\right](15)+ \\
v\left[\mathrm{C}_{\alpha}-\mathrm{C}_{\beta}\right](6)\end{array}$ \\
\hline 1256 & 1248 & $\begin{array}{l}\phi\left[\mathrm{H}_{\alpha}-\mathrm{C}_{\alpha}-\mathrm{C}\right](15)+v\left[\mathrm{C}_{\alpha}-\mathrm{C}_{\beta}\right](13)+ \\
\phi\left[\mathrm{H}_{\varepsilon \beta}-\mathrm{C}_{\varepsilon}-\mathrm{N}_{\xi}\right](12)+\phi\left[\mathrm{H}_{\alpha}-\mathrm{C}_{\alpha}-\mathrm{C}_{\beta}\right](9)+ \\
\phi\left[\mathrm{C}_{\delta}-\mathrm{C}_{\varepsilon}-\mathrm{H}_{\varepsilon \beta}\right](8)+v\left[\mathrm{C}_{\delta}-\mathrm{C}_{\varepsilon}\right](6)\end{array}$ & 1251 & 1248 & $\begin{array}{l}\phi\left[\mathrm{H}_{\varepsilon \beta}-\mathrm{C}_{\varepsilon}-\mathrm{N}_{\zeta}\right](18)+\phi\left[\mathrm{C}_{\delta}-\mathrm{C}_{\varepsilon}-\mathrm{H}_{\varepsilon \beta}\right](11)+ \\
v\left[\mathrm{C}_{\alpha}-\mathrm{C}_{\beta}\right](10)+\phi\left[\mathrm{H}_{\beta \beta}-\mathrm{C}_{\beta}-\mathrm{C}_{\gamma}\right](10)+ \\
\phi\left[\mathrm{C}_{\alpha}-\mathrm{C}_{\beta}-\mathrm{H}_{\beta \beta}\right](9)+v\left[\mathrm{C}_{\beta}-\mathrm{C}_{\gamma}\right](7)+v\left[\mathrm{C}_{\delta}-\mathrm{C}_{\varepsilon}\right](5)\end{array}$ \\
\hline 1237 & 1231 & $\begin{array}{l}\phi\left[\mathrm{H}_{\varepsilon \beta}-\mathrm{C}_{\varepsilon}-\mathrm{N}_{\zeta}\right](16)+\phi\left[\mathrm{H}_{\alpha}-\mathrm{C}_{\alpha}-\mathrm{C}_{\beta}\right](15)+ \\
\phi\left[\mathrm{H}_{\alpha}-\mathrm{C}_{\alpha}-\mathrm{C}\right](14)+\phi\left[\mathrm{C}_{\alpha}-\mathrm{C}_{\beta}-\mathrm{H}_{\beta \beta}\right](8)+ \\
\phi\left[\mathrm{C}_{\delta}-\mathrm{C}_{\varepsilon}-\mathrm{H}_{\varepsilon \beta}\right](7)+v\left[\mathrm{C}_{\alpha}-\mathrm{C}\right](6)+\phi\left[\mathrm{H}_{\beta \beta}-\mathrm{C}_{\beta}-\mathrm{C}_{\gamma}\right](6)+ \\
v\left[\mathrm{C}_{\beta}-\mathrm{C}_{\gamma}\right](6)\end{array}$ & 1224 & 1231 & $\begin{array}{l}\phi\left[\mathrm{H}_{\varepsilon \beta}-\mathrm{C}_{\varepsilon}-\mathrm{N}_{\zeta}\right](31)+\phi\left[\mathrm{H}_{\alpha}-\mathrm{C}_{\alpha}-\mathrm{C}\right](14)+ \\
\phi\left[\mathrm{H}_{\alpha}-\mathrm{C}_{\alpha}-\mathrm{C}_{\beta}\right](11)+\phi\left[\mathrm{C}_{\delta}-\mathrm{C}_{\varepsilon}-\mathrm{H}_{\varepsilon \beta}\right](8)\end{array}$ \\
\hline 1218 & $1218^{\mathrm{a}}$ & $\begin{array}{l}\phi\left[\mathrm{H}_{\varepsilon \beta}-\mathrm{C}_{\varepsilon}-\mathrm{N}_{\zeta}\right](40)+\phi\left[\mathrm{C}_{\delta}-\mathrm{C}_{\varepsilon}-\mathrm{H}_{\varepsilon \beta}\right](10)+ \\
\phi\left[\mathrm{C}_{\alpha}-\mathrm{C}_{\beta}-\mathrm{H}_{\beta \beta}\right](7)+\phi\left[\mathrm{C}_{\gamma}-\mathrm{C}_{\delta}-\mathrm{H}_{\delta \beta}\right](7)+ \\
\phi\left[\mathrm{H}_{\beta \beta}-\mathrm{C}_{\beta}-\mathrm{C}_{\gamma}\right](6)+\phi\left[\mathrm{H}_{\delta \beta}-\mathrm{C}_{\delta}-\mathrm{C}_{\varepsilon}\right](6)\end{array}$ & 1213 & 1218 & $\begin{array}{l}\phi\left[\mathrm{H}_{\varepsilon \beta}-\mathrm{C}_{\varepsilon}-\mathrm{N}_{\zeta}\right](21)+\phi\left[\mathrm{H}_{\alpha}-\mathrm{C}_{\alpha}-\mathrm{C}\right](14)+ \\
\phi\left[\mathrm{H}_{\alpha}-\mathrm{C}_{\alpha}-\mathrm{C}_{\beta}\right](14)+\phi\left[\mathrm{C}_{\alpha}-\mathrm{C}_{\beta}-\mathrm{H}_{\beta \beta}\right](8)+ \\
\phi\left[\mathrm{C}_{\delta}-\mathrm{C}_{\varepsilon}-\mathrm{H}_{\varepsilon \beta}\right](7)+\phi\left[\mathrm{H}_{\beta \beta}-\mathrm{C}_{\beta}-\mathrm{C}_{\gamma}\right](6)\end{array}$ \\
\hline 1138 & $1137^{\mathrm{a}}$ & $\begin{array}{l}\phi\left[\mathrm{C}_{\beta}-\mathrm{C}_{\gamma}-\mathrm{H}_{\gamma \beta}\right](24)+\phi\left[\mathrm{H}_{\gamma \beta}-\mathrm{C}_{\gamma}-\mathrm{C}_{\delta}\right](23)+ \\
\phi\left[\mathrm{H}_{\delta \beta}-\mathrm{C}_{\delta}-\mathrm{C}_{\varepsilon}\right](11)+\phi\left[\mathrm{C}_{\gamma}-\mathrm{C}_{\delta}-\mathrm{H}_{\delta \beta}\right](9)+v\left[\mathrm{~N}-\mathrm{C}_{\alpha}\right](9)\end{array}$ & 1136 & 1137 & $\begin{array}{l}\phi\left[\mathrm{C}_{\beta}-\mathrm{C}_{\gamma}-\mathrm{H}_{\gamma \beta}\right](26)+\phi\left[\mathrm{H}_{\gamma \beta}-\mathrm{C}_{\gamma}-\mathrm{C}_{\delta}\right](25)+ \\
\phi\left[\mathrm{H}_{\delta \beta}-\mathrm{C}_{\delta}-\mathrm{C}_{\varepsilon}\right](11)+\phi\left[\mathrm{C}_{\gamma}-\mathrm{C}_{\delta}-\mathrm{H}_{\delta \beta}\right](9)+ \\
\phi\left[\mathrm{C}_{\alpha}-\mathrm{C}_{\beta}-\mathrm{H}_{\beta \beta}\right](6)+v\left[\mathrm{~N}-\mathrm{C}_{\alpha}\right](6)\end{array}$ \\
\hline 1092 & 1092 & $\begin{array}{l}v\left[\mathrm{~N}-\mathrm{C}_{\alpha}\right](29)+\phi\left[\mathrm{C}_{\alpha}-\mathrm{C}_{\beta}-\mathrm{H}_{\beta \beta}\right](16)+ \\
\phi\left[\mathrm{H}_{\beta \beta}-\mathrm{C}_{\beta}-\mathrm{C}_{\gamma}\right](15)+v\left[\mathrm{C}_{\alpha}-\mathrm{C}\right](10)+\phi\left[\mathrm{H}_{\alpha}-\mathrm{C}_{\alpha}-\mathrm{C}\right](7)+ \\
\phi\left[\mathrm{H}_{\alpha}-\mathrm{C}_{\alpha}-\mathrm{C}_{\beta}\right](5)+\phi\left[\mathrm{H}_{\gamma \beta}-\mathrm{C}_{\gamma}-\mathrm{C}_{\delta}\right](5)\end{array}$ & 1086 & 1092 & $\begin{array}{l}\phi\left[\mathrm{C}_{\alpha}-\mathrm{C}_{\beta}-\mathrm{H}_{\beta \beta}\right](31)+\phi\left[\mathrm{H}_{\beta \beta}-\mathrm{C}_{\beta}-\mathrm{C}_{\gamma}\right](26)+ \\
\phi\left[\mathrm{C}_{\gamma}-\mathrm{C}_{\delta}-\mathrm{H}_{\delta \beta}\right](11)+\phi\left[\mathrm{H}_{\gamma \beta}-\mathrm{C}_{\gamma}-\mathrm{C}_{\delta}\right](8)+ \\
v\left[\mathrm{~N}-\mathrm{C}_{\alpha}\right](8)\end{array}$ \\
\hline 1078 & $1079^{a}$ & $\begin{array}{l}\phi\left[\mathrm{H}_{\beta \beta}-\mathrm{C}_{\beta}-\mathrm{C}_{\gamma}\right](18)+v\left[\mathrm{~N}-\mathrm{C}_{\alpha}\right](18)+ \\
\phi\left[\mathrm{C}_{\alpha}-\mathrm{C}_{\beta}-\mathrm{H}_{\beta \beta}\right](17)+\phi\left[\mathrm{C}_{\gamma}-\mathrm{C}_{\delta}-\mathrm{H}_{\delta \beta}\right](14)+ \\
\phi\left[\mathrm{H}_{\gamma \beta}-\mathrm{C}_{\gamma}-\mathrm{C}_{\delta}\right](9)+\phi\left[\mathrm{H}_{\delta \beta}-\mathrm{C}_{\delta}-\mathrm{C}_{\varepsilon}\right](6)+v\left[\mathrm{C}_{\alpha}-\mathrm{C}\right](5)\end{array}$ & 1070 & 1063 & $\begin{array}{l}\phi\left[\mathrm{H}_{\delta \beta}-\mathrm{C}_{\delta}-\mathrm{C}_{\varepsilon}\right](22)+\phi\left[\mathrm{C}_{\beta}-\mathrm{C}_{\gamma}-\mathrm{H}_{\gamma \beta}\right](19)+ \\
\phi\left[\mathrm{C}_{\gamma}-\mathrm{C}_{\delta}-\mathrm{H}_{\delta \beta}\right](19)+v\left[\mathrm{~N}-\mathrm{C}_{\alpha}\right](11)+\phi\left[\mathrm{H}_{\gamma \beta}-\mathrm{C}_{\gamma}-\mathrm{C}_{\delta}\right](11)\end{array}$ \\
\hline 1069 & $1063^{\mathrm{a}}$ & $\begin{array}{l}\phi\left[\mathrm{C}_{\beta}-\mathrm{C}_{\gamma}-\mathrm{H}_{\gamma \beta}\right](30)+\phi\left[\mathrm{H}_{\delta \beta}-\mathrm{C}_{\delta}-\mathrm{C}_{\varepsilon}\right](23)+ \\
\phi\left[\mathrm{H}_{\gamma \beta}-\mathrm{C}_{\gamma}-\mathrm{C}_{\delta}\right](21)+\phi\left[\mathrm{C}_{\gamma}-\mathrm{C}_{\delta}-\mathrm{H}_{\delta \beta}\right](15)\end{array}$ & 1066 & 1063 & $v\left[\mathrm{~N}-\mathrm{C}_{\alpha}\right](33)+\phi\left[\mathrm{H}_{\gamma \beta}-\mathrm{C}_{\gamma}-\mathrm{C}_{\delta}\right](12)+\phi\left[\mathrm{C}_{\beta}-\mathrm{C}_{\gamma}-\mathrm{H}_{\gamma \beta}\right](10)$ \\
\hline 987 & 983 & $\begin{array}{l}v\left[\mathrm{C}_{\alpha}-\mathrm{C}_{\beta}\right](29)+v\left[\mathrm{C}_{\delta}-\mathrm{C}_{\varepsilon}\right](10)+v\left[\mathrm{C}_{\varepsilon}-\mathrm{N}_{\zeta}\right](7)+ \\
\phi\left[\mathrm{H}_{\alpha}-\mathrm{C}_{\alpha}-\mathrm{C}_{\beta}\right](6)+\phi\left[\mathrm{C}_{\alpha}-\mathrm{C}_{\beta}-\mathrm{H}_{\beta \beta}\right](6)\end{array}$ & 1001 & 989 & $\begin{array}{l}v\left[\mathrm{C}_{\alpha}-\mathrm{C}_{\beta}\right](27)+v\left[\mathrm{C}_{\varepsilon}-\mathrm{N}_{\zeta}\right](14)+\phi\left[\mathrm{H}_{\alpha}-\mathrm{C}_{\alpha}-\mathrm{C}_{\beta}\right](7)+ \\
v\left[\mathrm{~N}-\mathrm{C}_{\alpha}\right](7)\end{array}$ \\
\hline 932 & 928 & $\begin{array}{l}v\left[\mathrm{C}_{\beta}-\mathrm{C}_{\gamma}\right](18)+v\left[\mathrm{C}_{\alpha}-\mathrm{C}\right](11)+v\left[\mathrm{C}_{\delta}-\mathrm{C}_{\varepsilon}\right](9)+ \\
\phi[\mathrm{O}-\mathrm{C} \cdots \mathrm{N}](8)+v[\mathrm{C} \cdots \mathrm{O}](7)+ \\
\phi\left[\mathrm{H}_{\beta \beta}-\mathrm{C}_{\beta}-\mathrm{C}_{\gamma}\right](7)+v[\mathrm{C}-\mathrm{N}](5)\end{array}$ & 926 & 928 & $\begin{array}{l}v\left[\mathrm{C}_{\beta}-\mathrm{C}_{\gamma}\right](33)+\phi\left[\mathrm{H}_{\beta \beta}-\mathrm{C}_{\beta}-\mathrm{C}_{\gamma}\right](9)+v\left[\mathrm{C}_{\delta}-\mathrm{C}_{\varepsilon}\right](8)+ \\
v\left[\mathrm{C}_{\varepsilon}-\mathrm{N}_{\zeta}\right](7)+v\left[\mathrm{C}_{\gamma}-\mathrm{C}_{\delta}\right](6)\end{array}$ \\
\hline 916 & 912 & $\begin{array}{l}v\left[\mathrm{C}_{\beta}-\mathrm{C}_{\gamma}\right](24)+v\left[\mathrm{C}_{\gamma}-\mathrm{C}_{\delta}\right](7)+v\left[\mathrm{~N}-\mathrm{C}_{\alpha}\right](6)+ \\
v\left[\mathrm{C}_{\varepsilon}-\mathrm{N}_{\zeta}\right](6)+v\left[\mathrm{C}_{\delta}-\mathrm{C}_{\varepsilon}\right](5)\end{array}$ & 909 & 912 & $\begin{array}{l}v\left[\mathrm{C}_{\alpha}-\mathrm{C}\right](9)+v\left[\mathrm{C}_{\beta}-\mathrm{C}_{\gamma}\right](8)+\phi\left[\mathrm{C}_{\delta}-\mathrm{C}_{\varepsilon}-\mathrm{H}_{\varepsilon \beta}\right](7)+ \\
v\left[\mathrm{C}_{\delta}-\mathrm{C}_{\varepsilon}\right](7)+\phi\left[\mathrm{H}_{\beta \beta}-\mathrm{C}_{\beta}-\mathrm{C}_{\gamma}\right](6)+\phi\left[\mathrm{H}_{\delta \beta}-\mathrm{C}_{\delta}-\mathrm{C}_{\varepsilon}\right](6)+ \\
v\left[\mathrm{C}_{\alpha}-\mathrm{C}_{\beta}\right](5)\end{array}$ \\
\hline 890 & 889 & $\begin{array}{l}\phi\left[\mathrm{C}_{\delta}-\mathrm{C}_{\varepsilon}-\mathrm{H}_{\varepsilon \beta}\right](17)+v\left[\mathrm{C}_{\gamma}-\mathrm{C}_{\delta}\right](16)+v\left[\mathrm{C}_{\beta}-\mathrm{C}_{\gamma}\right](12)+ \\
\phi\left[\mathrm{C}_{\gamma}-\mathrm{C}_{\delta}-\mathrm{H}_{\delta \beta}\right](8)+\phi\left[\mathrm{C}_{\beta}-\mathrm{C}_{\gamma}-\mathrm{H}_{\gamma \beta}\right](8)+ \\
\phi\left[\mathrm{H}_{\delta \beta}-\mathrm{C}_{\delta}-\mathrm{C}_{\varepsilon}\right](8)\end{array}$ & 886 & 891 & $\begin{array}{l}\phi\left[\mathrm{C}_{\delta}-\mathrm{C}_{\varepsilon}-\mathrm{H}_{\varepsilon \beta}\right](22)+\phi\left[\mathrm{C}_{\gamma}-\mathrm{C}_{\delta}-\mathrm{H}_{\delta \beta}\right](9)+ \\
v\left[\mathrm{C}_{\alpha}-\mathrm{C}\right](8)+\phi\left[\mathrm{H}_{\delta \beta}-\mathrm{C}_{\delta}-\mathrm{C}_{\varepsilon}\right](7)+\phi\left[\mathrm{C}_{\beta}-\mathrm{C}_{\gamma}-\mathrm{H}_{\gamma \beta}\right](5)+ \\
\phi\left[\mathrm{H}_{\varepsilon \beta}-\mathrm{C}_{\varepsilon}-\mathrm{N}_{\zeta}\right](5)\end{array}$ \\
\hline 751 & $751^{\mathrm{a}}$ & $\begin{array}{l}\omega[\mathrm{O}-\mathrm{C}](23)+\phi\left[\mathrm{C}_{\beta}-\mathrm{C}_{\gamma}-\mathrm{H}_{\gamma \beta}\right](16)+\omega[\mathrm{N}-\mathrm{H}](16)+ \\
\phi\left[\mathrm{H}_{\gamma \beta}-\mathrm{C}_{\gamma}-\mathrm{C}_{\delta}\right](10)+\phi\left[\mathrm{C}_{\delta}-\mathrm{C}_{\varepsilon}-\mathrm{H}_{\varepsilon \beta}\right](6)+ \\
\phi\left[\mathrm{H}_{\beta \beta}-\mathrm{C}_{\beta}-\mathrm{C}_{\gamma}\right](5)\end{array}$ & 769 & $762^{\mathrm{a}}$ & $\omega[\mathrm{O} \because \mathrm{C}](33)+\omega[\mathrm{N}-\mathrm{H}](20)+\phi\left[\mathrm{C}_{\delta}-\mathrm{C}_{\varepsilon}-\mathrm{H}_{\varepsilon \beta}\right](7)$ \\
\hline 742 & 738 & $\begin{array}{l}\omega[\mathrm{O} \cdots \mathrm{C}](15)+\phi\left[\mathrm{C}_{\beta}-\mathrm{C}_{\gamma}-\mathrm{H}_{\gamma \beta}\right](13)+ \\
\phi\left[\mathrm{H}_{\gamma \beta}-\mathrm{C}_{\gamma}-\mathrm{C}_{\delta}\right](12)+\omega[\mathrm{N}-\mathrm{H}](9)+\tau\left[\mathrm{C}_{\beta}-\mathrm{C}_{\gamma}\right](9)+ \\
\phi\left[\mathrm{C}_{\gamma}-\mathrm{C}_{\delta}-\mathrm{H}_{\delta \beta}\right](9)+\tau\left[\mathrm{C}_{\gamma}-\mathrm{C}_{\delta}\right](9)+\phi\left[\mathrm{H}_{\beta \beta}-\mathrm{C}_{\beta}-\mathrm{C}_{\gamma}\right](8)+ \\
\phi\left[\mathrm{H}_{\delta \beta}-\mathrm{C}_{\delta}-\mathrm{C}_{\varepsilon}\right](6)\end{array}$ & 744 & 738 & $\begin{array}{l}\phi\left[\mathrm{C}_{\beta}-\mathrm{C}_{\gamma}-\mathrm{H}_{\gamma \beta}\right](26)+\phi\left[\mathrm{H}_{\gamma \beta}-\mathrm{C}_{\gamma}-\mathrm{C}_{\delta}\right](19)+ \\
\phi\left[\mathrm{H}_{\beta \beta}-\mathrm{C}_{\beta}-\mathrm{C}_{\gamma}\right](15)+\tau\left[\mathrm{C}_{\beta}-\mathrm{C}_{\gamma}\right](14)+\tau\left[\mathrm{C}_{\gamma}-\mathrm{C}_{\delta}\right](8)\end{array}$ \\
\hline 735 & 738 & $\begin{array}{l}\phi\left[\mathrm{H}_{\delta \beta}-\mathrm{C}_{\delta}-\mathrm{C}_{\varepsilon}\right](25)+\phi\left[\mathrm{C}_{\delta}-\mathrm{C}_{\varepsilon}-\mathrm{H}_{\varepsilon \beta}\right](13)+ \\
\phi\left[\mathrm{C}_{\gamma}-\mathrm{C}_{\delta}-\mathrm{H}_{\delta \beta}\right](13)+\omega[\mathrm{O}-\mathrm{C}](12)+ \\
\phi\left[\mathrm{H}_{\beta \beta}-\mathrm{C}_{\beta}-\mathrm{C}_{\gamma}\right](7)+\tau\left[\mathrm{C}_{\delta}-\mathrm{C}_{\varepsilon}\right](6)+\omega[\mathrm{N}-\mathrm{H}](5)\end{array}$ & 735 & 738 & $\begin{array}{l}\phi\left[\mathrm{H}_{\delta \beta}-\mathrm{C}_{\delta}-\mathrm{C}_{\varepsilon}\right](31)+\phi\left[\mathrm{C}_{\gamma}-\mathrm{C}_{\delta}-\mathrm{H}_{\delta \beta}\right](17)+ \\
\phi\left[\mathrm{C}_{\delta}-\mathrm{C}_{\varepsilon}-\mathrm{H}_{\varepsilon \beta}\right](16)+\tau\left[\mathrm{C}_{\delta}-\mathrm{C}_{\varepsilon}\right](8)+\phi\left[\mathrm{H}_{\beta \beta}-\mathrm{C}_{\beta}-\mathrm{C}_{\gamma}\right](5)\end{array}$ \\
\hline 513 & 508 & $\begin{array}{l}\phi\left[\mathrm{C}_{\alpha}-\mathrm{C}-\mathrm{O}\right](20)+\phi\left[\mathrm{C}_{\alpha}-\mathrm{C}-\mathrm{N}\right](14)+ \\
\phi\left[\mathrm{N}-\mathrm{C}_{\alpha}-\mathrm{C}_{\beta}\right](14)+\phi\left[\mathrm{C}_{\beta}-\mathrm{C}_{\gamma}-\mathrm{C}_{\delta}\right](12)+ \\
v\left[\mathrm{C}_{\alpha}-\mathrm{C}\right](7)+v\left[\mathrm{~N}-\mathrm{C}_{\alpha}\right](5)\end{array}$ & 484 & 482 & $\begin{array}{l}\phi\left[\mathrm{C}_{\delta}-\mathrm{C}_{\varepsilon}-\mathrm{N}_{\zeta}\right](30)+\phi\left[\mathrm{C}_{\beta}-\mathrm{C}_{\gamma}-\mathrm{C}_{\delta}\right](14)+ \\
\phi\left[\mathrm{C}_{\alpha}-\mathrm{C}_{\beta}-\mathrm{C}_{\gamma}\right](7)+\phi\left[\mathrm{C}_{\alpha}-\mathrm{C}-\mathrm{O}\right](6)\end{array}$ \\
\hline 465 & 462 & $\phi\left[\mathrm{C}_{\delta}-\mathrm{C}_{\varepsilon}-\mathrm{N}_{\xi}\right](42)+\phi\left[\mathrm{C}_{\alpha}-\mathrm{C}_{\beta}-\mathrm{C}_{\gamma}\right](7)+v\left[\mathrm{C}_{\varepsilon}-\mathrm{N}_{\xi}\right](6)$ & 449 & $414^{\mathrm{a}}$ & $\begin{array}{l}\phi\left[\mathrm{C}_{\delta}-\mathrm{C}_{\varepsilon}-\mathrm{N}_{\zeta}\right](16)+\phi\left[\mathrm{C}_{\alpha}-\mathrm{C}-\mathrm{O}\right](7)+ \\
\phi\left[\mathrm{N}-\mathrm{C}_{\alpha}-\mathrm{C}_{\beta}\right](7)+\phi\left[\mathrm{C}_{\alpha}-\mathrm{C}-\mathrm{N}\right](7)+v\left[\mathrm{~N}-\mathrm{C}_{\alpha}\right](6)+ \\
\phi\left[\mathrm{H}_{\alpha}-\mathrm{C}_{\alpha}-\mathrm{C}\right](6)\end{array}$ \\
\hline 367 & $370^{\mathrm{a}}$ & $\begin{array}{l}\phi\left[\mathrm{C}-\mathrm{C}_{\alpha}-\mathrm{C}_{\beta}\right](18)+\phi\left[\mathrm{C}_{\alpha}-\mathrm{C}_{\beta}-\mathrm{C}_{\gamma}\right](13)+ \\
\phi\left[\mathrm{C}_{\delta}-\mathrm{C}_{\varepsilon}-\mathrm{N}_{\xi}\right](11)+\tau\left[\mathrm{C}_{\varepsilon}-\mathrm{N}_{\xi}\right](9)+\phi\left[\mathrm{C}-\mathrm{N}-\mathrm{C}_{\alpha}\right](8)+ \\
\phi[\mathrm{O}-\mathrm{C}-\mathrm{N}](5)+\omega[\mathrm{O}-\mathrm{C}](5)\end{array}$ & 371 & - & $\begin{array}{l}\phi\left[\mathrm{C}_{\alpha}-\mathrm{C}_{\beta}-\mathrm{C}_{\gamma}\right](17)+\phi\left[\mathrm{C}_{\delta}-\mathrm{C}_{\varepsilon}-\mathrm{N}_{\zeta}\right](13)+ \\
\phi\left[\mathrm{C}-\mathrm{C}_{\alpha}-\mathrm{C}_{\beta}\right](9)+\phi\left[\mathrm{N}-\mathrm{C}_{\alpha}-\mathrm{C}\right](7)+\phi\left[\mathrm{C}_{\gamma}-\mathrm{C}_{\delta}-\mathrm{C}_{\varepsilon}\right](6)+ \\
\tau\left[\mathrm{C}_{\varepsilon}-\mathrm{N}_{\zeta}\right](6)+\phi\left[\mathrm{C}-\mathrm{N}-\mathrm{C}_{\alpha}\right](5)\end{array}$ \\
\hline 341 & - & $\begin{array}{l}\phi\left[\mathrm{C}_{\gamma}-\mathrm{C}_{\delta}-\mathrm{C}_{\varepsilon}\right](23)+\phi\left[\mathrm{C}_{\alpha}-\mathrm{C}-\mathrm{O}\right](11)+ \\
\phi\left[\mathrm{C}_{\beta}-\mathrm{C}_{\gamma}-\mathrm{C}_{\delta}\right](11)+\phi[\mathrm{O}-\mathrm{C}-\mathrm{N}](10)+ \\
\phi\left[\mathrm{N}-\mathrm{C}_{\alpha}-\mathrm{C}_{\beta}\right](8)\end{array}$ & 347 & - & $\begin{array}{l}\phi\left[\mathrm{C}_{\gamma}-\mathrm{C}_{\delta}-\mathrm{C}_{\varepsilon}\right](16)+\phi\left[\mathrm{C}_{\beta}-\mathrm{C}_{\gamma}-\mathrm{C}_{\delta}\right](12)+ \\
\phi\left[\mathrm{C}_{\alpha}-\mathrm{C}-\mathrm{O}\right](11)+\phi\left[\mathrm{N}-\mathrm{C}_{\alpha}-\mathrm{C}_{\beta}\right](11)+ \\
\phi\left[\mathrm{N}-\mathrm{C}_{\alpha}-\mathrm{C}\right](8)+\phi[\mathrm{O}-\mathrm{C}-\mathrm{N}](8)+ \\
\phi\left[\mathrm{C}-\mathrm{N}-\mathrm{C}_{\alpha}\right](5)\end{array}$ \\
\hline 251 & - & $\begin{array}{l}\phi\left[\mathrm{N}-\mathrm{C}_{\alpha}-\mathrm{C}\right](19)+\tau\left[\mathrm{C}_{\alpha}-\mathrm{C}\right](17)+\tau[\mathrm{C}-\mathrm{N}](11)+ \\
\phi\left[\mathrm{C}-\mathrm{C}_{\alpha}-\mathrm{C}_{\beta}\right](8)+\tau\left[\mathrm{N}-\mathrm{C}_{\alpha}\right](8)+\phi\left[\mathrm{C}-\mathrm{N}-\mathrm{C}_{\alpha}\right](6)\end{array}$ & 236 & - & $\begin{array}{l}\phi\left[\mathrm{C}_{\gamma}-\mathrm{C}_{\delta}-\mathrm{C}_{\varepsilon}\right](20)+\phi\left[\mathrm{N}-\mathrm{C}_{\alpha}-\mathrm{C}_{\beta}\right](18)+ \\
\phi\left[\mathrm{C}_{\alpha}-\mathrm{C}-\mathrm{N}\right](7)+\phi[\mathrm{O}-\mathrm{C}-\mathrm{N}](7)+ \\
\tau[\mathrm{C}-\mathrm{N}](6)+\phi\left[\mathrm{N}-\mathrm{C}_{\alpha}-\mathrm{C}\right](5)\end{array}$ \\
\hline 216 & - & $\begin{array}{l}\phi\left[\mathrm{C}_{\gamma}-\mathrm{C}_{\delta}-\mathrm{C}_{\varepsilon}\right](17)+\phi\left[\mathrm{N}-\mathrm{C}_{\alpha}-\mathrm{C}_{\beta}\right](14)+ \\
\tau\left[\mathrm{C}_{\beta}-\mathrm{C}_{\gamma}\right](12)+\phi[\mathrm{O}-\mathrm{C}-\mathrm{N}](10)+ \\
\phi\left[\mathrm{C}-\mathrm{C}_{\alpha}-\mathrm{C}_{\beta}\right](7)\end{array}$ & 212 & - & $\begin{array}{l}\tau\left[\mathrm{C}_{\beta}-\mathrm{C}_{\gamma}\right](21)+\tau\left[\mathrm{C}_{\gamma}-\mathrm{C}_{\delta}\right](10)+\phi\left[\mathrm{C}-\mathrm{C}_{\alpha}-\mathrm{C}_{\beta}\right](8)+ \\
\phi\left[\mathrm{N}-\mathrm{C}_{\alpha}-\mathrm{C}\right](8)+\tau\left[\mathrm{N}-\mathrm{C}_{\alpha}\right](7)+\tau\left[\mathrm{C}_{\alpha}-\mathrm{C}_{\beta}\right](7)\end{array}$ \\
\hline
\end{tabular}


Table VII. (Continued)

\begin{tabular}{|c|c|c|c|c|c|}
\hline \multicolumn{2}{|c|}{ Freq. $/ \mathrm{cm}^{-1}$} & \multirow{2}{*}{ Assigments ( $\%$ P.E.D. at $\delta=0.00)$} & \multicolumn{2}{|c|}{ Freq. $/ \mathrm{cm}^{-1}$} & \multirow{2}{*}{ Assignments (\% P.E.D. at $\delta=0.56 \pi$ ) } \\
\hline Calcd & Obsd & & Calcd & Obsd & \\
\hline 169 & - & $\begin{array}{l}\tau\left[\mathrm{C}_{\gamma}-\mathrm{C}_{\delta}\right](18)+\phi\left[\mathrm{C}_{\beta}-\mathrm{C}_{\gamma}-\mathrm{C}_{\delta}\right](13)+\phi\left[\mathrm{C}_{\alpha}-\mathrm{C}_{\beta}-\mathrm{C}_{\gamma}\right](7)+ \\
\phi\left[\mathrm{C}-\mathrm{N}-\mathrm{C}_{\alpha}\right](6)\end{array}$ & 170 & - & $\begin{array}{l}\phi\left[\mathrm{C}_{\beta}-\mathrm{C}_{\gamma}-\mathrm{C}_{\delta}\right](20)+\phi\left[\mathrm{C} \cdots \mathrm{N}-\mathrm{C}_{\alpha}\right](11)+ \\
\phi\left[\mathrm{C}_{\alpha}-\mathrm{C}_{\beta}-\mathrm{C}_{\gamma}\right](10)+v\left[\mathrm{C}_{\alpha}-\mathrm{C}_{\beta}\right](7)+\tau\left[\mathrm{C}_{\delta}-\mathrm{C}_{\beta}-\mathrm{N}_{\gamma}\right](5)\end{array}$ \\
\hline 151 & - & $\begin{array}{l}\phi\left[\mathrm{C}_{\gamma}-\mathrm{C}_{\delta}-\mathrm{C}_{\varepsilon}\right](17)+\phi\left[\mathrm{C}_{\beta}-\mathrm{C}_{\gamma}-\mathrm{C}_{\delta}\right](17)+ \\
\tau\left[\mathrm{C}_{\gamma}-\mathrm{C}_{\delta}\right](14)+\phi\left[\mathrm{C}-\mathrm{C}_{\alpha}-\mathrm{C}_{\beta}\right](5)+\phi\left[\mathrm{C}_{\delta}-\mathrm{C}_{\varepsilon}-\mathrm{N}_{\xi}\right](5)\end{array}$ & 149 & - & $\begin{array}{l}\phi\left[\mathrm{C}_{\gamma}-\mathrm{C}_{\delta}-\mathrm{C}_{\varepsilon}\right](16)+\tau\left[\mathrm{C}_{\alpha}-\mathrm{C}\right](16)+\tau\left[\mathrm{C}_{\gamma}-\mathrm{C}_{\delta}\right](11)+ \\
\phi\left[\mathrm{C}_{\alpha}-\mathrm{C} \cdots \mathrm{N}\right](8)+\phi\left[\mathrm{C}_{\beta}-\mathrm{C}_{\gamma}-\mathrm{C}_{\delta}\right](6)+ \\
\phi\left[\mathrm{N}-\mathrm{C}_{-}-\mathrm{C}_{\beta}\right](6)\end{array}$ \\
\hline 95 & - & $\begin{array}{l}\tau\left[\mathrm{C}_{\gamma}-\mathrm{C}_{\delta}\right](20)+\tau\left[\mathrm{C}_{\delta}-\mathrm{C}_{\varepsilon}\right](10)+\phi\left[\mathrm{C}_{\alpha}-\mathrm{C}-\mathrm{N}\right](10)+ \\
\phi\left[\mathrm{C}-\mathrm{C}_{\alpha}-\mathrm{C}_{\beta}\right](9)+\phi\left[\mathrm{C}_{\alpha}-\mathrm{C}_{\beta}-\mathrm{C}_{\gamma}\right](8)\end{array}$ & 109 & - & $\begin{array}{l}\tau\left[\mathrm{C}_{\gamma}-\mathrm{C}_{\delta}\right](20)+\phi\left[\mathrm{C}-\mathrm{C}_{\alpha}-\mathrm{C}_{\beta}\right](18)+\phi\left[\mathrm{N}-\mathrm{C}_{\alpha}-\mathrm{C}\right](9)+ \\
\tau\left[\mathrm{C}_{\alpha}-\mathrm{C}\right](8)+\phi\left[\mathrm{C}-\mathrm{N}-\mathrm{C}_{\alpha}\right](6)\end{array}$ \\
\hline 90 & - & $\begin{array}{l}\tau\left[\mathrm{C}_{\alpha}-\mathrm{C}\right](37)+\tau\left[\mathrm{N}-\mathrm{C}_{\alpha}\right](17)+\phi\left[\mathrm{N}-\mathrm{C}_{\alpha}-\mathrm{C}\right](9)+ \\
\phi\left[\mathrm{C}-\mathrm{N}-\mathrm{C}_{\alpha}\right](6)\end{array}$ & 90 & - & $\begin{array}{l}\tau\left[\mathrm{C}_{\alpha}-\mathrm{C}\right](18)+\tau\left[\mathrm{C}_{\gamma}-\mathrm{C}_{\delta}\right](12)+\tau\left[\mathrm{N}-\mathrm{C}_{\alpha}\right](11)+ \\
\phi\left[\mathrm{C}_{\alpha}-\mathrm{C}_{\beta}-\mathrm{C}_{\gamma}\right](6)+\tau[\mathrm{C}-\mathrm{N}](6)+\tau\left[\mathrm{C}_{\delta}-\mathrm{C}_{\varepsilon}\right](6)\end{array}$ \\
\hline 32 & - & $\begin{array}{l}\tau\left[\mathrm{C}_{\alpha}-\mathrm{C}_{\beta}\right](39)+\tau\left[\mathrm{C}_{\beta}-\mathrm{C}_{\gamma}\right](9)+\tau\left[\mathrm{C}_{\gamma}-\mathrm{C}_{\delta}\right](7)+ \\
\phi\left[\mathrm{C}_{\alpha}-\mathrm{C}_{\beta}-\mathrm{C}_{\gamma}\right](6)+\phi\left[\mathrm{C}^{-} \mathrm{C}_{\alpha}-\mathrm{C}_{\beta}\right](5)\end{array}$ & 70 & - & $\tau\left[\mathrm{C}_{\beta}-\mathrm{C}_{\gamma}\right](29)+\tau\left[\mathrm{C}_{\alpha}-\mathrm{C}_{\beta}\right](24)+\tau\left[\mathrm{C}_{\delta}-\mathrm{C}_{\varepsilon}\right](29)$ \\
\hline 27 & - & $\begin{array}{l}\phi\left[\mathrm{N}-\mathrm{C}_{\alpha}-\mathrm{C}_{\beta}\right](26)+\phi\left[\mathrm{C}_{\alpha}-\mathrm{C}_{\beta}-\mathrm{C}_{\gamma}\right](15)+ \\
\phi\left[\mathrm{C}-\mathrm{N}-\mathrm{C}_{\alpha}\right](12)+\phi\left[\mathrm{C}_{\beta}-\mathrm{C}_{\gamma}-\mathrm{C}_{\delta}\right](9)+\tau\left[\mathrm{C}_{\alpha}-\mathrm{C}_{\beta}\right](5)\end{array}$ & 53 & - & $\begin{array}{l}\phi\left[\mathrm{C}_{\alpha}-\mathrm{C}_{\beta}-\mathrm{C}_{\gamma}\right](16)+\phi\left[\mathrm{N}-\mathrm{C}_{\alpha}-\mathrm{C}_{\beta}\right](13)+ \\
\tau\left[\mathrm{C}_{\alpha}-\mathrm{C}_{\beta}\right](12)+\phi\left[\mathrm{C}_{\beta}-\mathrm{C}_{\gamma}-\mathrm{C}_{\delta}\right](11)+\tau\left[\mathrm{C}_{\alpha}-\mathrm{C}\right](9)+ \\
\phi\left[\mathrm{C}-\mathrm{N}-\mathrm{C}_{\alpha}\right](6)\end{array}$ \\
\hline
\end{tabular}

${ }^{\text {a }}$ Frequencies also observed in Raman spectra.

in other $\alpha$-helical polypeptides. As $\delta$ increases the contribution of both $\mathrm{C}=\mathrm{O}$ wag and $\mathrm{N}-\mathrm{H}$ wag increases while that of side chain $\mathrm{C}-\mathrm{C}-\mathrm{H}$ bending decreases. At $\delta=0.56 \pi$ the mode appears at $769 \mathrm{~cm}^{-1}$ and is assigned to $762 \mathrm{~cm}^{-1}$ which is observed both in IR and Raman spectra.

At $\delta=0$ the observed frequencies $1063 \mathrm{~cm}^{-1}$ and $983 \mathrm{~cm}^{-1}$ are assigned to those calculated at $1069 \mathrm{~cm}^{-1}$ and $987 \mathrm{~cm}^{-1}$. These modes involve the bending of side chain $\mathrm{CH}_{2}$ groups. At the other end $(\delta=0.56 \pi)$ these are calculated at $1066 \mathrm{~cm}^{-1}$ and $1001 \mathrm{~cm}^{-1}$. The amide VII mode calculated at $251 \mathrm{~cm}^{-1}$ involves the backbone torsions and is a pure backbone mode at $\delta=0$. At $\delta=0.56 \pi$ the contribution of bending motion of side chain atoms also appears in this mode and the mode is calculated at $236 \mathrm{~cm}^{-1}$.

\section{Characteristic Features of Dispersion Curves}

One interesting feature of dispersion curves is the repulsion between various modes and their property of coming closer at a particular $\delta$ value. This repulsion is seen between pairs of modes of frequency $\left(1345 \mathrm{~cm}^{-1}\right.$ and $\left.1313 \mathrm{~cm}^{-1}\right),\left(1079 \mathrm{~cm}^{-1}\right.$ and $\left.1063 \mathrm{~cm}^{-1}\right),\left(641 \mathrm{~cm}^{-1}\right.$, $\left.575 \mathrm{~cm}^{-1}\right),\left(251 \mathrm{~cm}^{-1}\right.$ and $\left.216 \mathrm{~cm}^{-1}\right),\left(95 \mathrm{~cm}^{-1}\right.$ and $\left.90 \mathrm{~cm}^{-1}\right)$, and $\left(32 \mathrm{~cm}^{-1}\right.$ and $\left.27 \mathrm{~cm}^{-1}\right)$. Calculations show that these modes approach each other, potential energy distributions (PED)s of the two modes start mixing, at a particular value of $\delta$ they exchange character and diverge after repulsion.

The PED of 1345 and $1313 \mathrm{~cm}^{-1}$ modes starts mixing at $\delta=0.25 \pi$. At $0.45 \pi$ they exchange their PEDs and afterwards the lower one becomes constant while the upper starts increasing. Such exchange of PEDs and repulsion shows that these modes belong to the same symmetry species. In the modes of frequency 1079 and $1063 \mathrm{~cm}^{-1}$ the mixing of PEDs starts at $\delta=0.45 \pi$ and the exchange of PEDs takes place at $\delta=0.55 \pi$. The former one decreases till $\delta=0.50 \pi$ and for higher $\delta$ values it becomes constant. For $\delta>0.50 \pi$ the contribution of $\mathrm{N}-\mathrm{C}_{\alpha}$ stretch starts mixing in $1063 \mathrm{~cm}^{-1}$ mode and goes on increasing. The frequency of this mode decreases for $\delta$ values greater than $0.40 \pi$.

The modes 641 and $575 \mathrm{~cm}^{-1}$ come closer near helix angle and diverge afterwards. In the upper mode the contribution of $\mathrm{N}-\mathrm{H}$ and $\mathrm{C} \cdots \mathrm{O}$ wags increases till $\delta=0.50 \pi$ and decreases for higher $\delta$ values while in the lower mode the contribution of $\mathrm{C}=\mathrm{N}$ torsion decreases till $\delta=0.50 \pi$ and increases afterwards. The frequency $95 \mathrm{~cm}^{-1}$ has dominant contribution of side chain $\mathrm{C}-\mathrm{C}$ torsion. The contribution slowly decreases till $\delta=0.30 \pi$ and afterwards increases rapidly. A reverse trend is seen in the $90 \mathrm{~cm}^{-1}$ mode. Here the contribution of backbone $\mathrm{C}-\mathrm{C}$ torsion increases slowly till $\delta=0.25 \pi$ and decreases rapidly afterwards. Similar behavior is seen for other pairs of modes.

\section{Heat Capacity}

Recently Roles et al., ${ }^{11}$ Roles and Wunderlich, ${ }^{23}$ Wunderlich and $\mathrm{Bu},{ }^{16}$ and $\mathrm{Bu}$ et al. $^{24}$ reported experimental and theoretical heat capacities of synthetic as well as biological polypeptides. Their approach basically involves separation of vibrational spectra into group and skeletal vibrations. This approach has limitations specially when the PEDs of backbone and side chain modes are mixed up. This is very true in case of poly(L-lysine) below $1345 \mathrm{~cm}^{-1}$.

The frequency distribution function (density-of-states) obtained from dispersion curves are shown in Figures $3 \mathrm{~b}, 4 \mathrm{~b}, 5 \mathrm{~b}$, and $6 \mathrm{~b}$. The peaks correspond to the regions of high density-of-states. From this, the heat capacity of Plys has been calculated in the temperature range $50-500 \mathrm{~K}$. The modes which are purely skeletal, purely side chain and a mixture of these two are given in Tables III, VI, and VII, respectively. Their respective contributions to heat capacity are shown as curves $\mathrm{A}, \mathrm{B}$, and $\mathrm{C}$ in Figure 7. The total heat capacity (i.e., the sum of these three contributions) is represented as curve D in Figure 7 and the experimental data of Roles et al. ${ }^{11}$ are represented by triangles. Specific heat at low temperatures is sensitive to $g(v)$ in the low frequency region because the low frequency modes are much more sensitive to actual conformation of chain and side groups and there is strong coupling between them. The experimentally measured data agree well with the calculated data in the higher temperature range except for a scaling factor of 1.10. This scaling factor takes into account the con- 


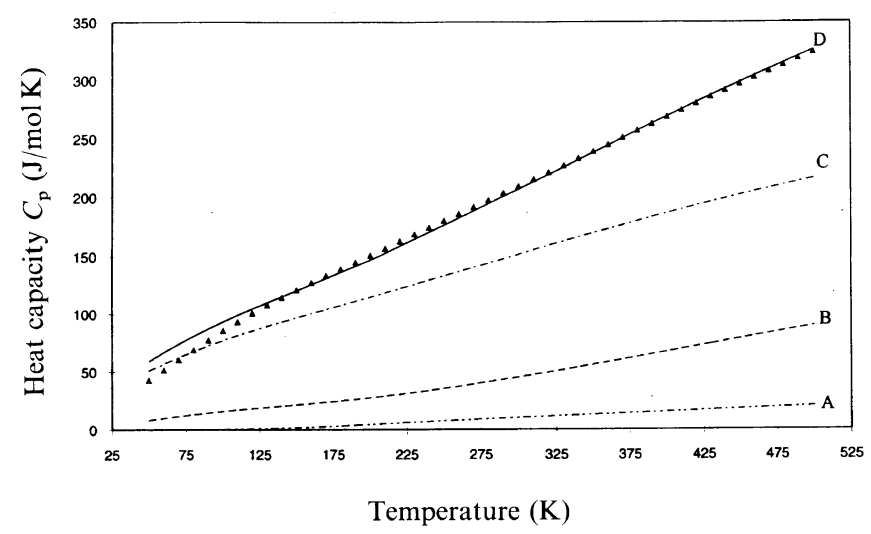

Figure 7. Variation of heat capacity $C_{\mathrm{p}}$ with temperature. [A $-\cdots-$, $\mathrm{B}----, \mathrm{C}-\cdot-$, and $\mathrm{D}-$ indicate backbone contribution, side-chain contribution, mix-mode contribution, and total heat capacity, respectively. The experimental points are shown by $\mathbf{A}$.]

stant separation between the experimental and theoretical curves which may arise due to possible error in experimental measurements and theory. It is clear from Figure 7 that the main contribution to the heat capacity comes from the coupling of backbone and side chain modes.

The contribution from the lattice modes, which arise due to the intramolecular interactions, is bound to make appreciable difference in heat capacity because of its sensitivity to these modes in the low frequency region. To take into account this contribution we have to calculate the dispersion curves for a three dimensional unit cell. In principle the evaluation of dispersion curves for a three dimensional system is possible but in practice it involves formulation and solution of the secular equation for the contents of a unit cell. This not only increases the dimensionality of the problem many fold but also brings in a large number of nonbonded interaction parameters difficult to visualize and quantify. To date, apart from polyglycine, polyalanine, and polyethylene, few problems have been solved for three dimensional structures. The intrachain interactions are generally of the same order of magnitude as the weaker interchain interactions. They affect the force constants and lead to crystal field splittings at the zone centre and zone boundary but the dominant assignments are not disturbed. Thus, in spite of several limitations, the present work using isolated chain model provides a good starting point for further basic studies on the thermodynamic behavior of polypeptides and proteins.

Acknowledgements. Financial assistance from the Council of Scientific and Industrial Research, New Delhi to N.K.M. and D.K. for the award of Junior Research
Fellowship and to V.D.G. for the C.S.I.R. Emeritus Scientist Project and to P.T. from the Department of Science and Technology under the Young Scientist Project is gratefully acknowledged.

\section{REFERENCES}

1. J. L. Koenig and P. L. Sutton, Biopolymers, 9, 1229 (1970).

2. B. Davidson and G. D. Fasman, Biochemistry, 6, 1616 (1967).

3. T. J. Yu, J. L. Lippert, and W. L. Peticolas, Biopolymers, 12, 2161 (1973).

4. M. Suwalsky and A. Llanos, Biopolymers, 16, 403 (1977).

5. D. Pederson, D. Gabriel, and J. Hermans, Jr., Biopolymers, 10, 2133 (1971).

6. R. F. Epand and H. A. Scheraga, Biopolymers, 6, 1383 (1968).

7. D. Puett, A. Cifferri, E. Bianchi, and J. Hermans, Jr., J. Phys. Chem., 71, 4126 (1967).

8. P. C. Painter and J. L. Koenig, Biopolymers, 15, 229 (1976).

9. H. Saito, T. Ohki, M. Kodama, and C. Nagata, Biopolymers, 17, 2587 (1978).

10. D. Carrier, H. H. Mantsch, and P. T. T. Wong, Biopolymers, 29, 837 (1990).

11. K. A. Roles, A. Xenopoulos, and B. Wunderlich, Biopolymers, 33, 753 (1993).

12. E. B. Wilson, J. C. Decius, and P. C. Cross, "Molecular Vibrations: The Theory of Infrared and Raman Vibrational Spectra," Dover Publications, New York, N.Y., 1980.

13. P. W. Higgs, Proc. R. Soc. (London), A220, 470 (1953).

14. S. Srivastava, Poonam Tandon, V. D. Gupta, and S. Rastogi, Polym. Prepr., Jpn., 37, 5401 (1996).

15. W. T. King, I. M. Mills, and B. L. Crawford, J. Chem. Phys., 27, 455 (1957).

16. B. Wunderlich and H. S. Bu, Thermochim. Acta, 119, 225 (1987).

17. L. Burman, Poonam Tandon, V. D. Gupta, and S. Rastogi, Polym. J., 28, 474 (1996).

18. M. V. Krishnan and V. D. Gupta, Chem. Phys. Lett., 6, 231 (1970).

19. Deepti Kapoor, Navnit K. Misra, Poonam Tandon, and V. D. Gupta, in Eur. Polym. J. to be published.

20. S. Srivastava, Poonam Tandon, V. D. Gupta, S. Rastogi, and C. Mehrotra, Polym. J., 29, 33 (1997).

21. L. Burman, Poonam Tandon, V. D. Gupta, and S. Srivastava, J. Macromol. Sci. Phys., B34, 379 (1995).

22. M. C. Chen and R. C. Lord, J. Am. Chem. Soc., 96, 4750 (1974).

23. K. A. Roles and B. Wunderlich, Biopolymers, 31, 477 (1991).

24. H. S. Bu, W. Aycock, Z. D. Cheng Stephen, and B. Wunderlich, Polymer, 29, 1486 (1988).

25. D. I. Bower and W. F. Maddams, "The Vibrational Spectroscopy of Polymers,' Cambridge University Press, New York, N.Y., 1989.

26. K. Itoh and T. Schimanouchi, Biopolymers, 9, 383 (1970).

27. M. Jackson, Parvez I. Haris, and D. Chapman, Biochim. Biophys. Acta, 998, 75 (1989).

28. E. R. Blout and H. Lenormant, Nature, 179, 960 (1957).

29. H. Susi, S. N. Timasheff, and L. Stevens, J. Biol. Chem., 242, 5460 (1967).

30. S. Song and S. A. Asher, J. Am. Chem. Soc., 111, 4295 (1989).

31. P. V. Scaria, M. Atreyi, and M. V. R. Rao, Biopolymers, 25, 2349 (1986).

32. A. Shibata, M. Yamamoto, T. Yamashita, J. S. Chiou, H. Kamaya, and I. Ueda, Biochemistry, 31, 5728 (1992). 